\title{
A Holistic Framework for Environmental Flows Determination in Hydropower Contexts
}

2013 Project Report

\section{Submitted to}

The United States Department of Energy (DOE)

April 2013

Submitted by

Ryan A. McManamay, Ph.D.

Postdoctoral Research Associate

ORNL Water Power Program

Mark S. Bevelhimer, Ph.D..

Senior Scientist

Oak Ridge National Laboratory

$\frac{\text { OAK RiDGE NATIONALLABORATORY }}{\text { managed by ut-battelle for the department of energy }}$ 


\section{DOCUMENT AVAILABILITY}

Reports produced after January 1, 1996, are generally available free via the U.S. Department of Energy (DOE) Information Bridge.

Web site http://www.osti.gov/bridge

Reports produced before January 1, 1996, may be purchased by members of the public from the following source.

National Technical Information Service

5285 Port Royal Road

Springfield, VA 22161

Telephone 703-605-6000 (1-800-553-6847)

TDD 703-487-4639

Fax 703-605-6900

E-mail info@ntis.fedworld.gov

Web site http://www.ntis.gov/support/ordernowabout.htm

Reports are available to DOE employees, DOE contractors, Energy Technology Data Exchange (ETDE) representatives, and International Nuclear Information System (INIS) representatives from the following source.

Office of Scientific and Technical Information

P.O. Box 62

Oak Ridge, TN 37831

Telephone 865-576-8401

Fax 865-576-5728

E-mail reports@adonis.osti.gov

Web site http://www.osti.gov/contact.html

This report was prepared as an account of work sponsored by an agency of the United States Government. Neither the United States Government nor any agency thereof, nor any of their employees, makes any warranty, express or implied, or assumes any legal liability or responsibility for the accuracy, completeness, or usefulness of any information, apparatus, product, or process disclosed, or represents that its use would not infringe privately owned rights. Reference herein to any specific commercial product, process, or service by trade name, trademark, manufacturer, or otherwise, does not necessarily constitute or imply its endorsement, recommendation, or favoring by the United States Government or any agency thereof. The views and opinions of authors expressed herein do not necessarily state or reflect those of the United States Government or any agency thereof. 


\title{
A Holistic Framework for Environmental Flows Determination in Hydropower Contexts
}

\section{Project Report}

\author{
Ryan A. McManamay and Mark S. Bevelhimer
}

April 2013

Prepared by

OAK RIDGE NATIONAL LABORATORY

Oak Ridge, Tennessee 37831-6283

managed by

UT-BATTELLE, LLC

for the

U.S. DEPARTMENT OF ENERGY

under contract DE-AC05-00OR22725

*Corresponding Author:

Ryan A. McManamay

Oak Ridge National Laboratory

1 Bethel Valley Road

Bldg 1505

Oak Ridge, TN 37831-6038

Email: mcmanamayra@ornl.gov

Phone: 865-241-8668 


\begin{abstract}
Among the ecological science community, the consensus view is that the natural flow regime sustains the ecological integrity of river systems. This prevailing viewpoint by many environmental stakeholders has progressively led to increased pressure on hydropower dam owners to change plant operations to affect downstream river flows with the intention of providing better conditions for aquatic biological communities. Identifying the neccessary magnitude, frequency, duration, timing, or rate of change of stream flows to meet ecological needs in a hydropower context is challenging because the ecological responses to changes in flows may not be fully known, there are usually a multitude of competing users of flow, and implementing environmental flows usually comes at a price to energy production. Realistically, hydropower managers must develop a reduced set of goals that provide the most benefit to the identified ecological needs.

As a part of the Department of Energy (DOE) Water Power Program, the Instream Flow Project (IFP) was carried out by Oak Ridge National Laboratory (ORNL), Pacific Northwest National Laboratory (PNNL), and Argon National Laboratory (ANL) as an attempt to develop tools aimed at defining environmental flow needs for hydropower operations. The application of these tools ranges from national to site-specific scales; thus, the utility of each tool will depend on various phases of the environmental flow process. Given the complexity and sheer volume of applications used to determine environmentally acceptable flows for hydropower, a framework is needed to organize efforts into a staged process dependent upon spatial, temporal, and functional attributes. By far, the predominant domain for determining environmental flows related to hydropower is within the Federal Energy Regulatory Commission (FERC) relicensing process. This process can take multiple years and can be very expensive depending on the scale of each hydropower project. The utility of such a framework is that it can expedite the environmental flow process by 1) organizing data and applications to identify predictable relationships between flows and ecology, and 2) suggesting when and where tools should be used in the environmental flow process. In addition to regulatory procedures, a framework should also provide the coordination for a comprehensive research agenda to guide the science of environmental flows. This research program has further reaching benefits than just environmental flow determination by providing modeling applications, data, and geospatial layers to inform potential hydropower development.

We address several objectives within this document that highlight the limitations of existing environmental flow paradigms and their applications to hydropower while presenting a new framework catered towards hydropower needs. Herein, we address the following objectives: 1) Provide a brief overview of the Natural Flow Regime paradigm and existing environmental flow frameworks that have been used to determine ecologically sensitive stream flows for hydropower operations. 2) Describe a new conceptual framework to aid in determining flows needed to meet ecological objectives with regard to hydropower operations. The framework is centralized around determining predictable relationships between flow and ecological responses. 3) Provide evidence of how efforts from ORNL, PNNL, and ANL have filled some of the gaps in this broader framework, and suggest how the framework can be used to set the stage for a research agenda for environmental flow.
\end{abstract}




\section{ACKNOWLEDGEMENTS}

The authors would like to acknowledge and thank following individuals and programs for providing comments and support of this report.

DOE Water Power Program:

- $\quad$ Hoyt Battey

- $\quad$ Thomas Heibel

Oak Ridge National Laboratory:

- $\quad$ Brennan T. Smith

- $\quad$ Shelaine C. Hetrick

- Shih-Chieh Kao

- Henriette I. Jager

Virginia Polytechnic Institute and State University

- $\quad$ Emmanuel A. Frimpong 


\section{TABLE OF CONTENTS}

ABSTRACT .

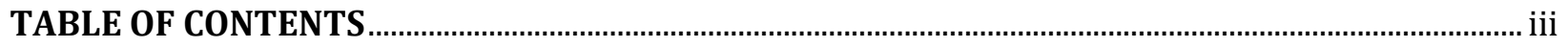

LIST OF FIGURES

LIST OF TABLES............................................................................................................................................

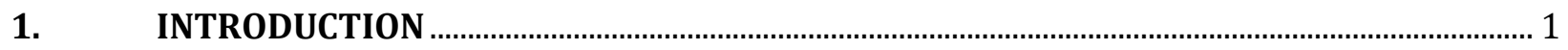

1.1 The Natural Flow Regime Paradigm and Relations to Hydropower ............................. 2

1.2 Existing Environmental Flow Frameworks …...................................................................... 3

2. AN ALTERNATIVE ENVIRONMENTAL FLOW FRAMEWORK FOR HYDROPOWER .......... 8

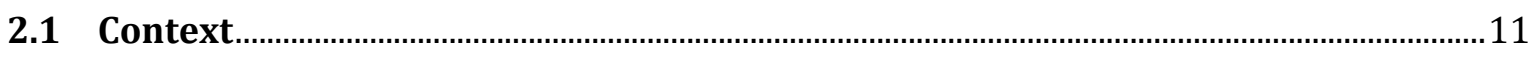

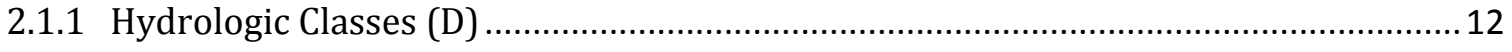

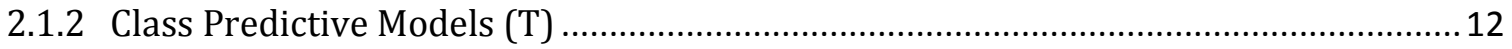

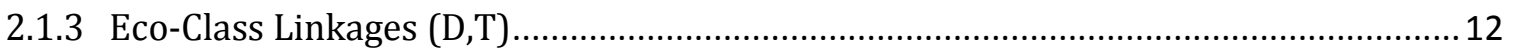

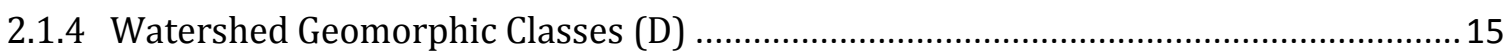

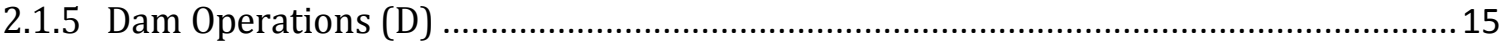

2.2 Assessment

2.2.1 Daily-Seasonal Flow Statistics (T) ........................................................................ 19

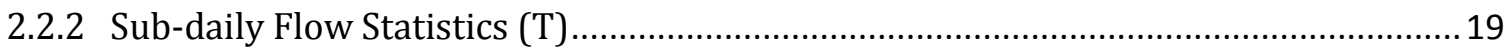

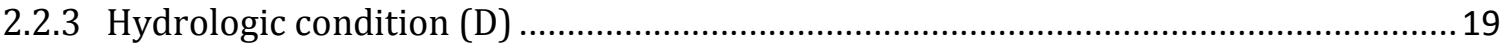

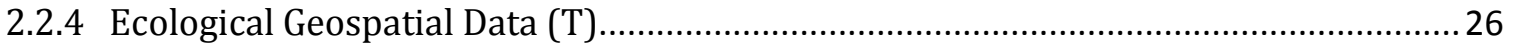

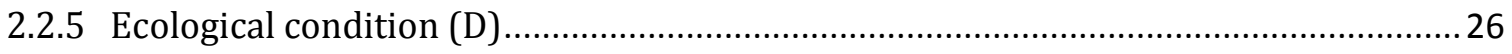

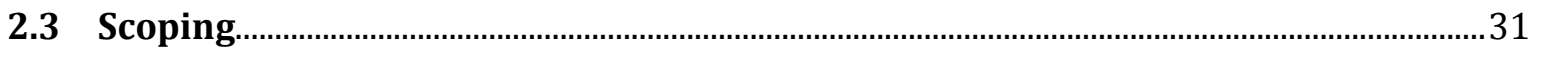

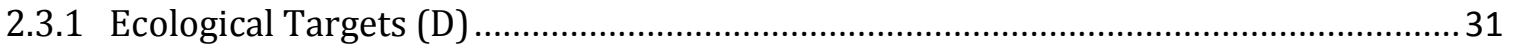

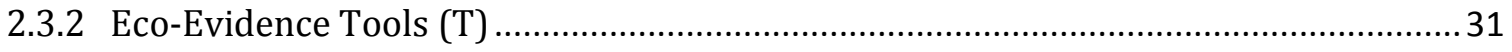

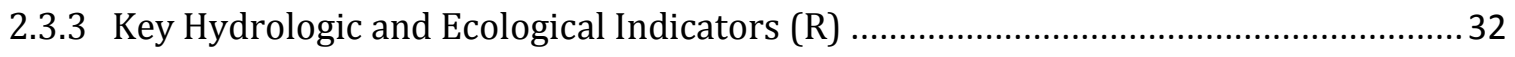

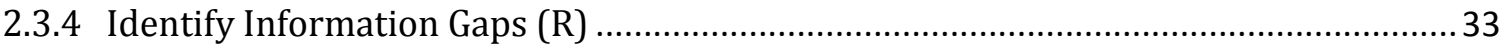

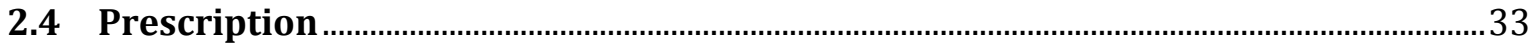

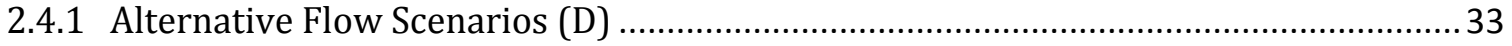

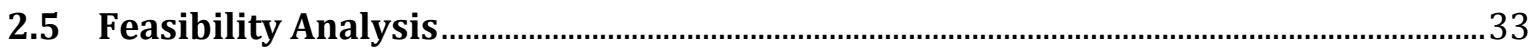

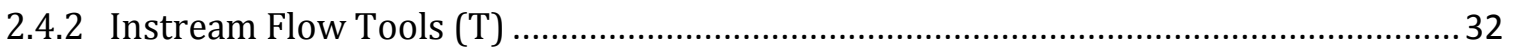

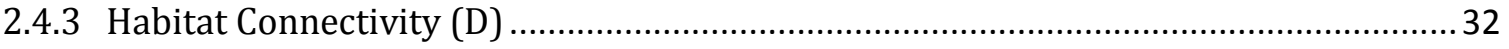

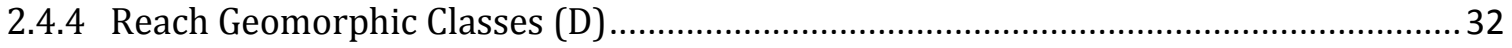




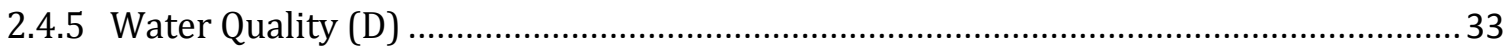

3. APPLYING THE HEFLOW FRAMEWORK TO HYDROPOWER CONTEXTS..........................38

4. THE HEFLOW FRAMEWORK, MARKET ACCELERATION, AND ACCOMPLISHMENTS...39

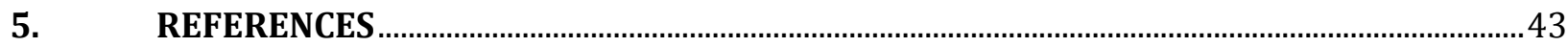

6. APPENDIX- ABSTRACTS OF DOE SUPPORTED INSTREAM FLOW PROJECT WORK .....51 


\section{LIST OF FIGURES}

Figure 1. The Ecological Limits of Hydrologic Alteration (ELOHA) framework. From Poff et al. (2010).5

Figure 2. Five core elements make up the application steps of the HEFLOW framework and operate across variable spatio-temporal scales. The core elements are synonymous with application steps with increasing detail and finer spatial resolution. All elements can span the entire hydrologic resolution axis (annual to sub-daily time-scales).

Figure 3. The HEFLOW framework. Each of the core elements are steps or applications ranging from national to site-specific spatial resolutions. Long vertical rectangular boxes represent data layers whereas dashed-line white boxes represent tools that connect data layers. Orange boxes represent stakeholder input information (e.g. ecological targets) or framework output (e.g. key hydrologic/ecological indicators). The framework hinges upon the development of predictable flow-ecology relationships (central arrow) which occurs in the scoping phase and connects the first half of the framework to the second half.

Figure 4. US hydrologic classes ranging from intermittent to highly stable flows. Variables within each class can be represented by a typical range of variation or normal tendency (box and whisker plots). Box and whisker plots represent distribution of mean annual runoff and daily variation according to 15 hydrologic classes. Modified from McManamay et al. (2013b).

Figure 5. Developing a predictive linkage between the hydrologic classification and fish traits applied to 8-digit hydrologic unit codes (top). Box and whisker plots of distributions of traits (proportion of periodic species, left, and serial spawning index, right) within hydrologic classes. Hydrologic classes were sorted from high runoff to highly intermittent. Modified from McManamay et al. (2013a).

Figure 6. Physiographic provinces across the US that could be used in a geomorphic classification. (Inset) An example of a stream-reach gradient classification conducted for the North Eastern US (data from WMI 2012).

Figure 7. Example of a simple hydropower project containing single dam and powerhouse (Kingsford Project) and a complex project containing multiple developments, dams within a development, and separate structures for dams and powerhouses (East Fork Project). Reaches A and B experience extremely different flows despite being located within the same project. Reach A refers to the bypass channel (flow-diverted reach) below Bear Creek Dam characterized by extreme low flow volumes. Reach B is located below the Cedar Cliff Powerhouse tailrace and receives high flow pulses.

Figure 8. Tri-point continuum of hydrologic and ecological condition for a given hydropower project. A project may (A) have little modification to flow, (B) modify the timing and distribution of flows without large losses to annual water budget, or (C) divert large quantities of water thereby reducing the water budget thereby limiting the quantity and quality of habitat. Likewise a project may (D) have little modification to natural biodiversity, (E) have highly modified river communities that support ecosystem services, such as sportfisheries, or (F) have extensive losses to ecosystem services. Associations among hydrologic and endpoints are likely to exist; however, ecological endpoints should not be viewed as directly related to hydrologic endpoints (e.g. B does not necessarily result in E).

Figure 9. Dam-regulated stream gages $(n=1,180)$ assigned to hydrologic classes using the classpredictive model (top). Outliers (red dots) detected using Mahalanobis distances calculated between each regulated gage and the centroid of the unregulated gages within each hydrologic class (bottom). The size of the dots represent the total upstream dam storage above each gage corrected for drainage area. From McManamay et al. (2013b). 
Figure 10. A comparison of hydrologic conditions for peaking and run-of-river hydropower projects assessed using sub-daily or daily statistics. The comparison yielded opposing results for subdaily and daily statistics. Sub-daily statistics yield more consistent results than daily statistics when assessing hydrologic conditions among operations. From Bevelhimer et al. (2013).

Figure 11. An assessment of the hydrologic condition of the Snake River below Hells Canyon Dam, Idaho. (A) Using class prediction models, USGS gage 13290450 was classified as a Snowmelt 2 type stream. (B) Comparisons of the current flow below Hells Canyon Dam to the Snowmelt 2 hydrologic profile $\left(10^{\text {th }}\right.$ to $95^{\text {th }}$ percentile of standardized flows) reveal departures from the relative magnitude of annual maxima and seasonal baseflows. Standardized flow calculated by dividing each year by maximum flow.

Figure 12. (A) Assessing departures in a given variable for the Snake River below Hells Canyon Dam from the central tendency represented as the inter-quartile range for the Snowmelt 2 Class (gray section of box and whisker plot represent interquartile range (IQR) whereas error bars represent $95^{\text {th }}$ percent confidence interval). (B) Percent changes of USGS 13290450 from the IQR of the Snowmelt 2 class for 27 daily flow statistics.

Figure 13. Comparison of the Brule River for peaking conditions (Pre-relicensing, 1989-1995) and runof-river conditions (Post-relicensing, 1996-2013) with respect to the interquartile ranges of 23 daily hydrologic statistics represented by the Super-stable Groundwater Class (Class 5) and the Snowmelt 2 Class (Class 8). Although the predictive model suggested shared membership between Class 5 and 8 , results of the hydrologic condition assessment suggest that Class 5 is more appropriate. Large changes in most hydrologic variables from pre- to post- relicensing were not observed. However, for evidence changes post-relicensing, hydrologic conditions were more similar to the normal tendency represented by Class 5.

Figure 14. Examples of ecological geospatial data sets. (A) Fish sampling point locations provided by two data sources for the U.S.. (B) Multiple sources can be combined to create composite datasets for regions, such as fish sampling locations within the Appalachicola-Flint and Alabama Coosa Tallapoosa River basins. (C) Combined datasets can be summarized to create localized ecological layers to support assessing hydropower project ecological condition.

Figure 15. An example of an Eco-Evidence approach (modified from McManamay et al. 2013d). Based on literature compilation, work groups can develop databases representing a regional knowledge base. The database can be used to extract flow-ecology relationships, develop predicted responses to flow restoration, or isolate key hydrologic/ecological indicators for a specific context.

Figure 16. (A) Compilation of regional hydrologic information (USGS gages and dam spillage) and fish sampling locations for the Upper Tennessee River Basin. (B) Based on multivariate models, simulations can yield predictive flow-ecology relationships to predict fish richness or riparian vegetation responses to changes in flow. Modified from McManamay et al. (2013c).

Figure 17. Implementation of flows following application of HEFLOW framework. Adaptive management should be used to monitor flows after implementation. However, for all parties to agree to adaptive management, hydropower and environmental stakeholders should both have some level of mutual perceived risk. Based on results of monitoring, collaborative decision making can be used to determine final flow regime for the length of the new license.

Figure 18. Accomplishments made by ORNL, PNNL, and ANL during the course of the Instream Flow Project (IFP) supported by DOE. Each cell represents a data set or tool that falls within a particular element/or application within the HEFLOW framework (see Figure 2 for reference). Accomplishments made related to- and unrelated to current DOE support are also provided. 


\section{LIST OF TABLES}

Table 1. Mode-of-operation classes are listed along with the frequency of 432 power plants surveyed within each class, the range in generation capacity in megawatts (MW), and the description of each class. Generation capacity is the capacity of a facility to generate electricity given the flow volume, hydraulic

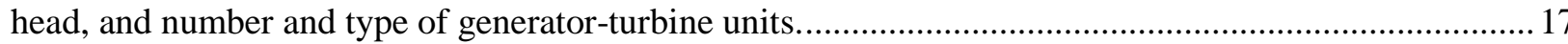

Table 2. Seven sub-daily flow statistics and their descriptions (from Bevelhimer et al. 2013)...............20

Table 3. Examples of alternative flow scenario components to be tested during feasibility studies. Alternative scenarios can represent one to many different flows within each component and/or one to many different combinations of components. 
(THIS PAGE LEFT BLANK INTENTIONALLY) 


\section{INTRODUCTION}

Among the ecological science community, the consensus view is that the natural flow regime (i.e. the dynamic quantity, timing, and variation of natural stream flows) sustains the ecological integrity of river systems (Poff et al. 1997; Bunn and Arthington 2002; Poff et al. 2010). This prevailing viewpoint by many environmental stakeholders has progressively led to increased pressure on hydropower dam owners to change plant operations to affect downstream river flows with the intention of providing better conditions for aquatic biological communities. These proposed changes often include moving away from peaking operations to run-of-river operations, at the expense of energy losses, based on the assumption that downstream biological communities will improve under more natural flow regimes. It is our opinion that instream flows are the greatest obstacle to conventional hydropower market acceleration.

Although many examples exist where project operations have moved from peaking to more natural run-of-river conditions (Haas et al. 2013), a complete reinstatement of natural flow conditions is unfeasible for many project operations due to large losses in energy or losses in services provided by projects, e.g. recreational boating releases, tailwater fisheries. In an ideal world, a reasonable compromise is found by identifying key characteristics of the flow regime that are amenable or nonconducive to healthy aquatic communities and using that information to identify possible mitigation opportunities. However, understanding the ecological needs of the aquatic community and using that information to implement environmental flows for regulated rivers is a complex process, complicated by the operational, socio-economic, physio-chemical, morphologic, and finally, ecological context of each and every dam (McCartney 2009).

Defining these key elements of the flow-regime to improve downstream river communities is the "golden nugget" of environmental flow science. The seemingly simple question, "How much flow does a river need?", remains to be answered (Richter et al. 1996) - in part, because it is not a simple question, but a very complex issue plagued by varying spatio-temporal ecological and societal needs. One of the greatest needs for environmental flow science to date is creating general and transferable relationships between flow and ecology (Poff and Zimmerman 2010). These relationships cannot replace site-specific knowledge, but provide grounds for streamlining the process of defining environmental flow needs for a particular river system. In addition, tools that support the process of developing flow-ecology relationships reduce the complexity of defining the critical aspects of the flow regime by focusing efforts on key aspects of the river's hydrograph and key ecological targets.

As a part of the Department of Energy (DOE) Water Power Program, the Instream Flow Project (IFP) was carried out by Oak Ridge National Laboratory (ORNL), Pacific Northwest National Laboratory (PNNL), and Argon National Laboratory (ANL) as an attempt to develop tools aimed at defining environmental flow needs for hydropower operations (see Figure 18). The application of these tools ranges from national to site-specific scales; thus, the utility of each tool will depend on various phases of the environmental flow process. For example, tools at the national scale may provide a geographic context to identify flow-related issues and organize environmental flow recommendations whereas tools at the local, site-specific scale may provide an assessment of the feasibility of different alternative flow 
scenarios (Figure 18). Given the complexity and sheer volume of applications used to determine environmentally acceptable flows for hydropower, a framework is needed to organize efforts into a staged process dependent upon spatial, temporal, and functional attributes. By far, the predominant domain for determining environmental flows related to hydropower is within the Federal Energy Regulatory Commission (FERC) relicensing process. This process can take multiple years and can be very expensive depending on the scale of each hydropower project. The utility of such a framework is that it can expedite the environmental flow process by 1) organizing data and applications to identify predictable relationships between flows and ecology, and 2) suggesting when and where tools should be used in the environmental flow process. In addition to regulatory procedures, a framework should also provide the coordination for a comprehensive research agenda to guide the science of environmental flows. This research program has further reaching benefits than just environmental flow determination by providing modeling applications, data, and geospatial layers to inform potential hydropower development.

We address several objectives within this document that highlight the limitations of existing environmental flow paradigms and their applications to hydropower while presenting a new framework catered towards hydropower needs. Our objectives include the following:

- Provide a brief overview of the Natural Flow Regime paradigm and existing environmental flow frameworks that have been used to determine ecologically sensitive stream flows for hydropower operations.

- Describe a new conceptual framework to aid in determining flows needed to meet ecological objectives with regard to hydropower operations. The framework is centralized around determining predictable relationships between flow and ecological responses.

- Provide evidence of how efforts from ORNL, PNNL, and ANL have filled some of the gaps in this broader framework, and suggest how the framework can be used to set the stage for a research agenda for environmental flow (Figure 18).

\subsection{The Natural Flow Regime Paradigm and Relations to Hydropower}

The Natural Flow Regime is defined as the magnitude, frequency, duration, timing, and rate of change of flow events that characterize the hydrology of natural river environments (Poff et al. 1997; Bunn and Arthington 2002; Poff et al. 2010). Flow has been termed a "master-variable" that organizes the physio-chemical template of river habitats that aquatic and riparian communities depend upon for survival (Power et al. 1995; Poff et al. 1997). For example, flow variability has been shown to create and maintain habitats (Trush et al. 2000), which are essential to supporting riverine communities (Poff and Allan 1995; Bunn and Arthington 2002; Herbert et al. 2003; Pyron and Lauer 2004). Not surprisingly, extensive literature suggests that losses to hydrologic variability can cause dramatic changes in river communities (Pringle et al. 2000; Roy et al. 2005; Freeman and Marcinek 2006; Poff and Zimmerman 2010; Carlisle et al. 2011).

Many studies have assessed the hydrologic effects of dam operations, the majority of which have documented reductions in natural flow variability among daily, seasonal, or annual time scales (Magillan and Nislow 2001, 2005; Pyron and Neumann 2008; Poff et al. 2007). The ecological effects of unnatural 
subdaily flow variations, like that caused by hydropower peaking, has also received substantial attention (for a review, see Cushman 1985). Because the overall habitat template within river systems is partially organized by flow, deviation from naturally variable flow regimes affects multiple habitat factors simultaneously. For example, reductions in the hydrologic connectivity of a river with its floodplain alter the morphology of the channel that carries its flow. Altered timing, magnitude, frequency, and duration of floods that provide pulse flows to riparian zones can induce changes in organic and sediment inputs (Poff et al. 1997; Trush et al. 2000; Nislow et al. 2002). Likewise, losses in larger flood events tend to decrease bankfull area, decrease sinuousity, and increase riparian vegetation due to encroachment (Gordon and Meentemeyer 2006). Flow and temperature are also related (Caissie 2006). For example, larger releases from dams result in greater thermal buffering capacity whereas reductions in discharge below reservoirs result in lower thermal buffering capacity and generally, higher annual temperatures (Caissie 2006). However, much of the deviation in temperature in regulated rivers from natural regimes results from releases from stratified layers of the impoundment. For example, hypolimnetic releases can cause dramatic reductions in temperature (Pozo et al. 1997; Krause et al. 2005) whereas releases from the surface of the reservoir can lead to increases (Lessard and Hayes 2003; Caissie 2006).

\subsection{Existing Environmental Flow Frameworks}

Globally, a great deal of effort has been devoted to improving flows for ecological communities in regulated river systems (Tharme 2003; Roni et al. 2008). During the late 1960s, the field of 'instream flows' arose as an attempt to bring balance to the various uses of water flowing through river systems (Annear et al. 2004). Instream flow (IF) is defined as the amount of water needed in a stream to adequately support downstream uses, including sustaining ecological communities (Annear et al. 2004). The term 'environmental flows' began being used in the 1990s as a more holistic description of the quantity, timing, and quality of water flows required to sustain riverine ecosystems and human livelihoods that depend on them. Determining the amount and timing of flows needed to sustain ecosystems under a full array of competing uses is a daunting challenge. Not surprisingly, there is a full spectrum of techniques used to assess IF needs, depending on objectives and the degree and type of competing uses. The Instream Flow Council (IFC) recognizes over 30 different documented methods, ranging from low effort (office only) to high effort (intensive field work and modeling). For simplification, Annear et al. (2004) categorizes IF methods into one of three types: 1) Standard setting, 2) Incremental, and 3) Monitoring/diagnostic. Standard setting is typically policy-driven and sets limits to determine appropriate flow regimes (Stalnaker et al. 1995). Incremental methods are among the most time-intensive and analyze stage-specific ecological/habitat responses within a stream channel to compare alternative flow scenarios (Stalnaker et al. 1995; Annear et al. 2004). Monitoring/diagnostic methods assess river conditions over time with respect to flow regimes and emphasize the importance of adaptive management. The methods can be further categorized by the resource component being analyzed: 1) hydrology, 2) biology, 3) geomorphology, 4) water quality, and/or 5) connectively (floodplain inundation).

Among the simplest standard-setting IF techniques is the Tennant or Montana method. The Tennant method evaluates estimated habitat quality (i.e. biological response) at various flows using 
limited field measurements, hydrologic records, and photographs of the stream channel (Tennant 1976). This method can be used as a reconnaissance level tool for determining acceptable seasonably various flow magnitudes in situations where there is little or no heavy competing uses (Annear et al. 2004). Other simple reconnaissance level approaches may be used to assess and characterize complex hydrologic conditions of river systems in order to provide ecologically meaningful metrics and to prioritize various aspects of the hydrograph for future emphasis. Richter et al. (1996) originally developed the Indicators of Hydrologic Alteration (IHA) and followed with the Range of Variability Approach (RVA) (Richter et al. 1997), both monitoring/assessment approaches. The methods are dependent upon the presence of pre and post-dam-regulation discharge data or nearby unregulated comparable stream gages. Multiple ecologically relevant hydrologic indices are calculated for pre and post-regulation periods of record and then compared. However, the IHA and RVA methods are limited in that they typically have no quantitative relationship to in-stream ecological needs, unless accompanied by biological monitoring data. Of the most complex IF techniques, Instream-Flow-Incremental-Methodology (IFIM) approaches assess hydrology, biology, sediment transport, and water quality under various flow regime alternatives (Bovee et al. 1998). Intensive field work and modeling is used to predict habitat over a range of given flows. IFIM approaches can range from simple relations between hydrologic indices and aquatic habitats to more complex hydrodynamic models, which can be linked to multiple components of the river ecosystem (Tharme 2003).

Although even the most complex IFIM approaches can be scientifically sound and provide assessments of management alternatives, IFIM approaches may only be applicable to the reach under study (Moir et al. 2005) and may not consider the full complexity of all ecosystem components (Anderson et al. 2006). Recently, more tools have been developed as holistic alternatives to traditional IF techniques to provide information in complex management situations. For example, King and Louw (1998) developed the Building Block Methodology (BBM) to address all riverine ecosystem component needs (including societal) using existing knowledge and expert opinion in a structured workshop process. Brown et al. (2000) developed the Downstream Response to Imposed Flow Transformations (DRIFT), which builds upon the BBM approach but develops a quantitative database of biophysical and sociological linkages to flow regimes and then evaluates biophysical, social, and economic responses under various flow scenarios.

Within most holistic approaches, making predictable assessments of potential ecological responses to changes in flow regimes requires quantitative information on the relationships between hydrology and key components of river ecology; however, many environmental flow assessments proceed without the ideal knowledge base required (Arthington et al. 2003). Recent environmental flow management has been thwarted, at least to some degree, by the absence of quantitative and transferable relationships between flow and ecology (Poff et al. 2010; Poff and Zimmerman 2010). Flow-ecology relationships represent a relationship between changes in flow (e.g. $25 \%$ decrease in daily flow magnitude) and changes in some ecological response (e.g. 30\% decrease in fish richness) (Poff et al. 2010; Poff and Zimmerman 2010). Isolating these general, widely-applicable, flow-ecology relationships has been proposed as the template needed to inform water policy negotiations, including roundtable discussion among environmental and hydropower stakeholders. 
Flow-ecology relationships, once developed, can provide 'rules of thumb' for streams within a given region or of a particular type (Poff et al. 2010). The need for standardized flow-ecology relationships provided the motivation for creating flow classifications where streams are grouped according to similar hydrologic properties (e.g. Poff and Ward 1989; Poff 1996; Kennard et al. 2010); therefore, instead of managing for every individual river, classes of rivers with similar hydrologic properties can be used to develop and expedite the process of determining environmental flow recommendations (Arthington et al. 2006). The need for quantitative information to support environmental flow development led to the development of a process known as the Ecological Limits of Hydrologic Alteration (ELOHA) (Figure 1, Poff et al. 2010). ELOHA is the product of a consensus view of 19 international scientists and leaders in the field of environmental flow science (Poff et al. 2010) and has been considered the most holistic environmental flow framework to date (Richter et al. 2012). ELOHA has been partially applied in at least six states and three interstate river basins to determine environmental flow needs at the regional scale (Kendy et al. 2012); however, its applicability to hydropower operations has received little attention (except see McManamay et al. 2013c).

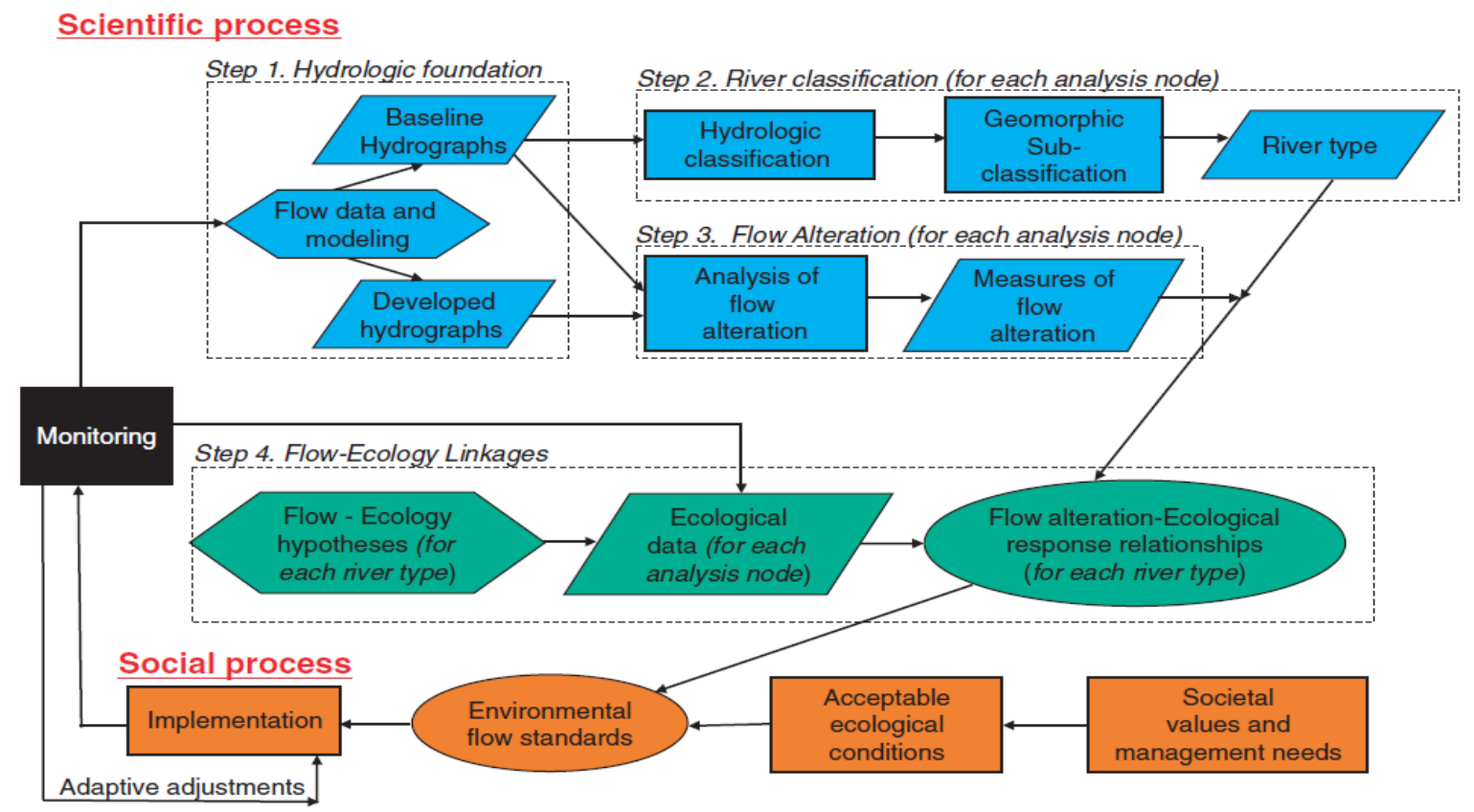

Figure 1. The Ecological Limits of Hydrologic Alteration (ELOHA) framework. From Poff et al. (2010).

Within the ELOHA framework, river classes provide a stratified approach to assess hydrologic alterations and flow-ecology relationships (Arthington et al. 2006; Poff et al. 2010). The five specific steps of the ELOHA procedure include: 1) building a hydrologic foundation of baseline or "natural" conditions, 2) classifying river types based on natural hydrology along with potential geomorphic subclassification), 3) assessing flow alterations within each river class in relation to baseline conditions, 4) determining flow-ecology relationships for each river class, and 5) determining socially acceptable 
ecological limits, implementing water policies, and using adaptive management to adjust policies (Figure 1, Poff et al. 2010). Flow-ecology relationships (Step 4) represent univariate percent changes in ecology and flow from natural or baseline conditions to the current or altered condition (Poff et al. 2010; Poff and Zimmerman 2010). Although Poff et al. (2010) admit that other environmental variables (e.g. temperature) may confound relationships between flow and ecology, very little quantitative basis is provided for incorporating more specific context (e.g. geomorphology or dam operation) into determining environmental flows.

To our knowledge, the only assessment of the ELOHA procedure for regulated rivers is provided by McManamay et al. (2013c) who tested the utility of ELOHA in informing environmental flow applications for hydropower dams in the Upper Tennessee River Basin. Although ELOHA sufficiently provided a template to construct a database of baseline hydrologic information, McManamay et al. (2013c) suggested that ELOHA was insufficient in guiding environmental flow applications for specific hydropower contexts for the following reasons: 1) Univariate relationships between flow and ecology exclude morphology, temperature, and fragmentation and produce results insufficient to develop quantitative and predictable relationships. 2) ELOHA relies on social roundtable discussion to identify the relative consequences of scientific uncertainty in implementing environmental flows based on univariate flow-ecology relationships. McManamay et al. (2013c) argued that this uncertainty is too high for regulated river contexts and should be decreased through more scientific assessments, such as multivariate model-building. 3) The ELOHA framework uses baseline conditions to formulate flowecology relationships, which then inform the process of developing environmental flow standards (Figure 1). In many situations, baseline ecologic information may underrepresent the variation found in regulated rivers because it is usually absent or is only available for smaller-sized streams. In addition, baseline targets may be inappropriate for regulated systems because the baseline is not desired or only addresses specific ecological needs compared to many users of regulated rivers (e.g. tailwater fisheries, etc). 4) ELOHA is a preventative framework whereas most US hydropower contexts need a proactive framework. Specifically, ELOHA sets socially acceptable "ecological limits" on hydrologic alterations so that water policy standards can be implemented. While ELOHA is a very flexible framework, its strengths lie in the fact that it predicts the ecological consequences of hydrologic alteration prior to the hydrologic alteration taking place. Thus ELOHA may perform well in a development planning context. Rivers that are currently regulated, however, need a restoration framework, i.e. one that assesses the current condition and then suggests alternative flows for improving habitat conditions. 5) The process of using ELOHA to inform management on a case-by-case basis may be limited given the scope and context of each river system. US dam facilities are typically managed on a site-by-site basis within very specific contexts based on dam operations, ecological and socio-economic needs, and physio-chemical considerations (McCartney 2009). Thus, any framework will not remove the need for individual attention in regulated river contexts, but should provide a template to expedite information assimilation needed to address more specific needs.

According to Richter et al. (2012), the ELOHA framework is the best "available balance between scientific rigor and cost of application for setting environmental flow standards." However, the associated costs of applying ELOHA frameworks to specific jurisdictions range from $\$ 100 \mathrm{k}$ to $\$ 2 \mathrm{M}$, depending on jurisdiction size and the extent of available biologic and hydrologic information (Richter et 
al. 2012). Even more so, time constraints are proving to be a larger obstacle to implementing the ELOHA framework, especially in areas of intense competing water uses (Richter et al. 2012). Although there are specific needs that remain to be addressed, the ELOHA framework provides some useful elements that we build upon to create robust framework for use in hydropower situations. Rather than re-construct frameworks for individual jurisdictions, U.S. hydropower operations could benefit from a universal continental-wide framework. 


\section{AN ALTERNATIVE ENVIRONMENTAL FLOW FRAMEWORK FOR HYDROPOWER}

Over 1000 hydropower projects across the United States are subject to FERC relicensing procedures (which typically re-occur on a 30-50 year basis; FERC 2013). Relicensing procedures typically take 5-10 years. While relicensing ensures assessments of all project-related resources, assessments of environmental flow issues typically require the most attention and time. Part of the relicensing process involves evaluating how project operations have negatively impacted natural resources, including stream flows and associated aquatic organisms. In addition, after many studies and roundtable discussion, recommendations for habitat improvement (e.g. increased minimum flows, reestablishing peak flows) and monitoring are approved. Although pre-project conditions (e.g. pre-dam hydrology) can be useful in informing the relicensing and recommendation process, re-establishing the full spectrum of pre-disturbance natural flows while maintaining some semblance of energy production is unlikely. Hence, the baseline condition in a hydropower context cannot nor should not be fully dependent upon pre-disturbance conditions, but dependent upon current conditions and how those conditions can be improved. In other words, US hydropower regulations require a restorative rather than preventative environmental flow framework.

Another challenge is that many frameworks base environmental flow recommendations solely on hydrologic conditions (Richter et al. 1996) or regional flow-ecology relationships (Poff et al. 2010) without taking into account hydrologic interactions with the stream channel. Separating a river channel from the streamflow it carries is problematic (Trush et al. 2000). Complex ecohydraulics result from the dynamic interactions between flow and channel morphology, which, in part, determine the ability of an organism to carry out its life history requirements and exist in a given riverscape (Fausch et al. 2002). In addition, water quality conditions can change dramatically depending on flow conditions (Caisse 2006). Coarse assessments of flow-ecology relationships can be informative in isolating key ecological and hydrologic indicators for site-specific studies; however, reach-specific feasibility analyses are still required to develop suitable environmental flow recommendations.

As a part of the Integrated Licensing Process (ILP), scoping is used to identify and determine issues related to each hydropower project that should be addressed by FERC (FERC 2013). Within the scoping process, stakeholders can request applicants to conduct studies and gather information to address issues and information gaps, such as the degree of biological improvement potentially provided by alternative flow scenarios. Studies outlined in the scoping process, if justified and executed, can be expensive in terms of time and money. For example, even after studies are completed, applicants must hold meetings with stakeholders to discuss results with the potential that study plans may be further modified. Thus, hydropower and environmental stakeholders would benefit from an organized approach to expedite the preliminary application and scoping process by identifying information gaps in the knowledge base, creating studies that more accurately address ecological needs, and prioritizing future efforts. In relation to environmental flows, a framework advantageous to the ILP could expedite the assessment of current project conditions, the identification and prioritization of relevant hydrologic and ecologic indicators, and the process of developing alternative flow scenarios based on ecological needs; 
thus, more time could be allocated to creating and conducting feasibility studies rather than assessment studies.

Identifying the neccessary magnitude, frequency, duration, timing, or rate of change of stream flows to meet ecological needs in a hydropower context is challenging because the ecological responses to changes in flows may not be fully known; there are usually a multitude of competing users of flow and implementing environmental flows usually comes at a price to energy production. In addition, selecting the most appropriate ecologically-sensitive alternative stream flows is a daunting task, plagued by an over-abundance of hydrologic metrics (Olden and Poff 2003) and competing objectives. Realistically, hydropower managers must develop a reduced set of goals that provide the most benefit to the identified ecological needs. Reducing the uncertainty about which flow characteristics are most important from an ecological perspective could likely lead to compromise solutions that provide both valuable ecological services and load-following capabilities. While we suggest a modified approach to determining environmental flows for hydropower needs, we are not proposing a full paradigm shift. Indeed, we utilize many of the ideas proposed in current environmental flow frameworks, such as assessments of regional patterns in natural hydrology, hydrologic alterations, and flow-ecology relationships. For example, pre-disturbance hydrologic condition can be useful for determining the hydrologic context of a given hydropower facility. However, rather than environmental flow recommendations be based on these coarse assessments, we suggest that these assessments aid in identifying information gaps and isolating specific hydrologic and ecologic elements to guide site-specific analyses. An alternative framework could organize how these elements inform the process of narrowing down environmental flow needs for hydropower situations.

In order to develop ecologically relevant stream flows to inform hydroelectric operations at the national, regional, or site-specific scales, we have constructed a framework that provides five core elements: 1) context, 2) assessment, 3) scoping, 4) prescription, and 5) feasibility. These five core elements represent different stages of applications in hydropower relicensing/impact assessment and inform management across various spatio-temporal scales (Figure 2). Specifically, context is provided at larger scales to characterize the hydrologic, geomorphic, physio-chemical, and operational setting around each hydropower project. Assessment can be conducted at national or regional scales and includes fully describing the current hydrologic/ecologic conditions in relation to ecological objectives, obtaining predictive flow-ecological needs relationships, and identifying key hydrologic and ecological indicators. Scoping is used to isolate and prioritize information gaps at regional or site-specific scales. Based upon best available knowledge at site-specific scales, prescription presents a series of alternative flow scenarios based the assessment and scoping stages. Lastly, analyses are conducted to determine the feasibility (i.e. ecological benefit versus impacts to project economics) of alternative flows at the site-specific scale. Each of the five core elements make up the steps of the Hydropower Environmental Flow (HEFLOW) framework (Figure 3). Each step is represented by foundational data layers or data sets (D). Specific tools (T) utilize information from data layers and link core elements as they move from one stage to the next (Figure 3). Similar to the ELOHA framework, the central theme of the process requires creating flow-ecology relationships (arrow within the Scoping element, Figure 3); however, a much larger degree of relevant information must be compiled and assimilated prior to developing these relationships. In addition, these flow-ecology relationships help identify information gaps and structure site-specific 
analyses, rather than replace them. Ultimately, following the last stage of the framework (i.e. feasibility analysis), flows are implemented and followed by adaptive management to monitor and make adjustments.

Realistically, a framework cannot be, nor should it be, a step-by-step guide to implement environmental flows in regulated river systems. While the framework organizes information and planning processes, it requires input and roundtable discussion. Specifically, the context and assessment elements, along with associated tools, may be available in conventional background datasets and packages. However, the scoping, prescription, and feasibility elements will require individual attention and input based on each specific hydropower project. For example, context and assessment will inform the scoping process based on larger scale scientific process; however, determining the ecological targets is a social element that requires stakeholder input.

In the sections that follow, we provide a brief description of tools and datasets that ORNL, PNNL, and ANL have developed during the course of the IFP. Each of these datasets (D) and tools (T) has begun to fill in the gaps of this larger proposed framework. Ultimately, we envision that each of these elements will require adequate research to fully support the framework structure. In a tangible sense, the core elements provide the structure for a larger centralized data repository and application capacity that can serve both hydropower and environmental stakeholders.

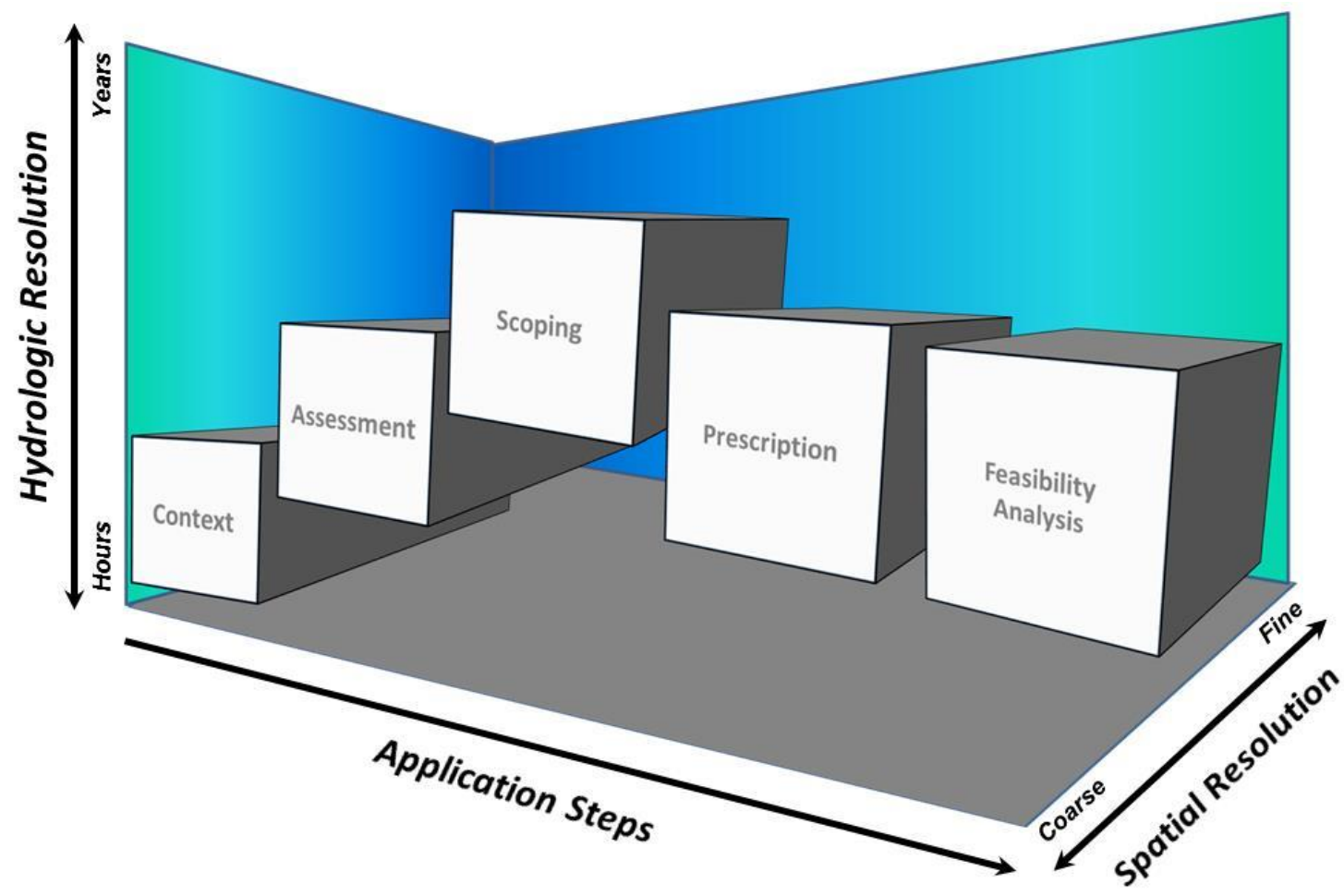

Figure 2. Five core elements make up the application steps of the HEFLOW framework and operate across variable spatio-temporal scales. The core elements are synonymous with application steps with increasing detail and finer spatial resolution. All elements can span the entire hydrologic resolution axis (annual to sub-daily time-scales). 


\subsection{Context}

A common trend in the development of frameworks for broad-scale management is creating classification systems (Rosgen 1994; Poff 1996; Brandt 2000; Wehrly et al. 2003; Wollock et al. 2004; Sowa et al. 2007). Because classification systems consolidate variability, they provide a context to organize and generalize management actions at the national scale. Classes also provide an approach to stratify analyses. For example, a dam in the Pacific Northwest is unlikely to have the same hydrologic, geomorphic, and biophysical effect as a dam in the Southeast. Different hydro-geomorphic settings as well as the type of dam operations will determine the extent and nature of hydrologic and geomorphic impacts associated with hydropower development. Likewise, hydro-geomorphic contexts also provide a preliminary estimate of what restoration or mitigation measures may be required, given the type of dam operation.

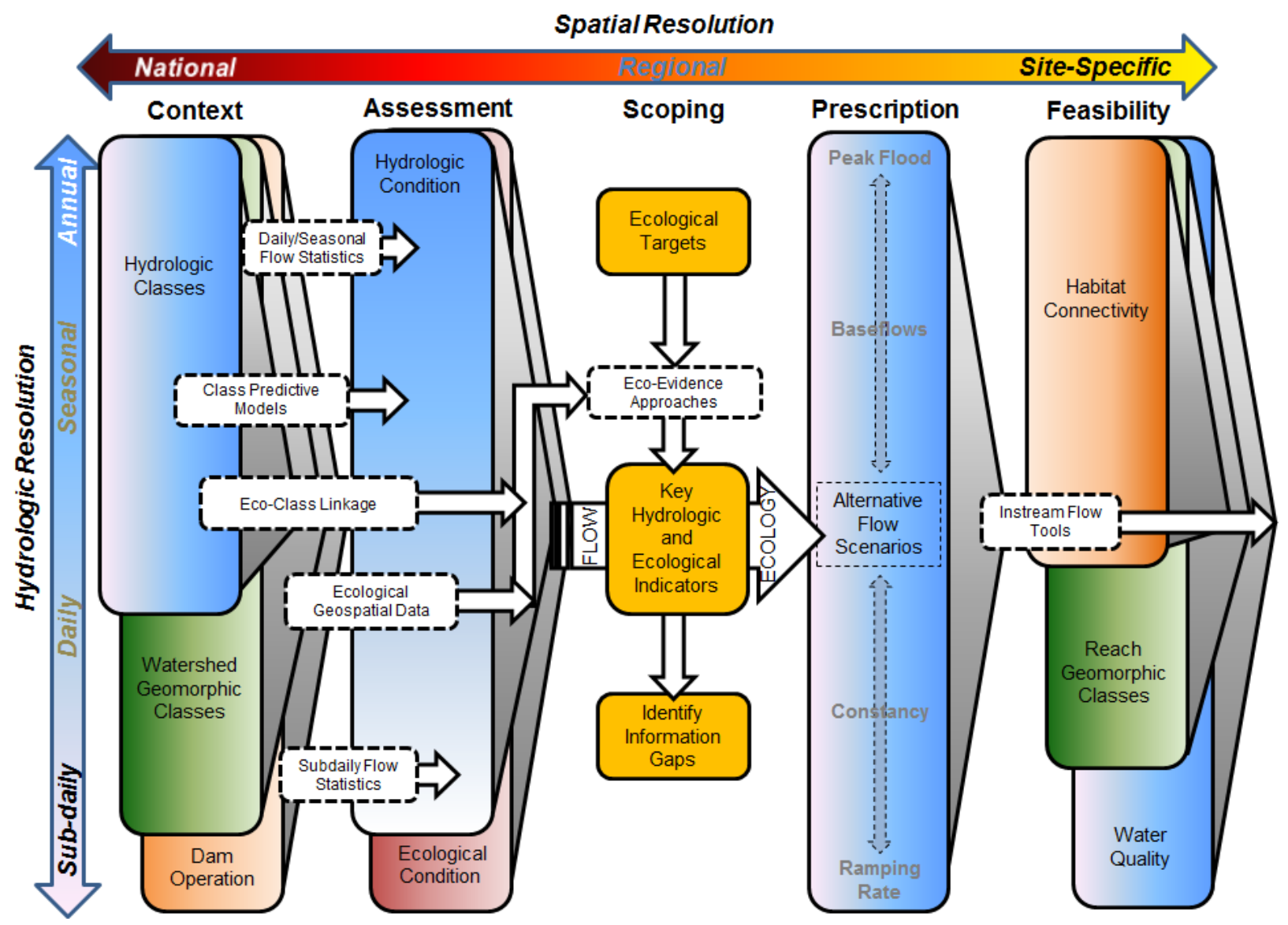

Figure 3. The HEFLOW framework. Each of the core elements are steps or applications ranging from national to site-specific spatial resolutions. Long vertical rectangular boxes represent data layers whereas dashed-line white boxes represent tools that connect data layers. Orange boxes represent stakeholder input information (e.g. ecological targets) or framework output (e.g. key hydrologic/ecological indicators). The framework hinges upon the development of predictable flow-ecology relationships (central arrow) which occurs in the scoping phase and connects the first half of the framework to the second half. 


\subsubsection{Hydrologic Classes (D)}

Poff et al. (2007) proposed that dam-induced hydrologic effects could be generalized and further suggested that losses in regionally-distinct hydrologic types resulted in a homogenization of fluvial habitats across continental scales. Indeed, there are some general hydrologic elements that show somewhat universal responses to dams. For example, typically, peak flood magnitudes are diminished and minimum flows are inflated in river systems below dams (Richter et al. 1996; Magillan and Nislow 2001 and 2005; Pyron and Neumann 2008; Poff et al. 2007; Fitzhugh and Vogel 2011). Likewise, increases in reversals, i.e. abrupt positive/negative changes in flow, are common results of dam operation (Richter et al. 1996; Mathews and Richter 2007). Although some generalities exist, McManamay et al. (2012) showed that regulated streams within the Southeastern US were not homogeneous and displayed highly variable responses in monthly, seasonal, and baseflows. Furthermore, McManamay et al. (2012) found that hydrologic responses to dams were more predictable when stratified by hydrologic class membership.

In order to provide a hydrologic setting for hydropower operations, McManamay et al. (2013b) developed a hydrologic classification for the continental U.S. using daily discharge information from 2,618 USGS stream gages unregulated by dams (Figure 4). Fifteen distinct hydrologic classes were isolated representing a full spectrum of hydrologic types from unstable intermittent to very stable, high runoff systems (Figure 4). For a given hydrologic metric, each class provides a range of variation, i.e. normal tendency (Figure 4). Thus, hydrologic classes provide a template to assess departures from the normal tendency. Although the normal tendency represents the natural flow regime, it is not meant to override or place an agenda on specific flow objectives. However, understanding departures from normal tendencies provides a relative comparison of where project operations fit into a larger picture.

\subsubsection{Class Predictive Models (T)}

Many times, stream flow information is not available for a particular hydropower project prior to dam construction. Thus, landscape and climate information may be critical to determining class membership. Two types of class-predictive models were created using hydrologic metrics and landscape/climate variables depending on the availability of hydrologic data (McManamay et al. 2013b). If pre-dam regulation stream flow information is readily available, a hydrologic classification tool can be used. In the absence of adequate stream flow information, the landscape/climate predictive tool can be used.

\subsubsection{Eco-Class Linkages (D,T)}

The utility of classification systems in ecological management lies in their ability to consolidate substantial information into digestible units thereby providing a more efficient means to achieve conservation objectives. Specifically, classification systems are valuable in that they can be used to group sites with similar character (Frimpong and Angermeier 2010), stratify analyses for monitoring and/or experimentation (Wolock et al. 2004), prioritize aquatic conservation areas (Snelder et al. 2007), and generalize ecological responses to disturbances (Bailey 1983). Sokal (1974) suggests that although 
classifications have many practical and applied outcomes, hypothesis generation is the greatest determinant of success.
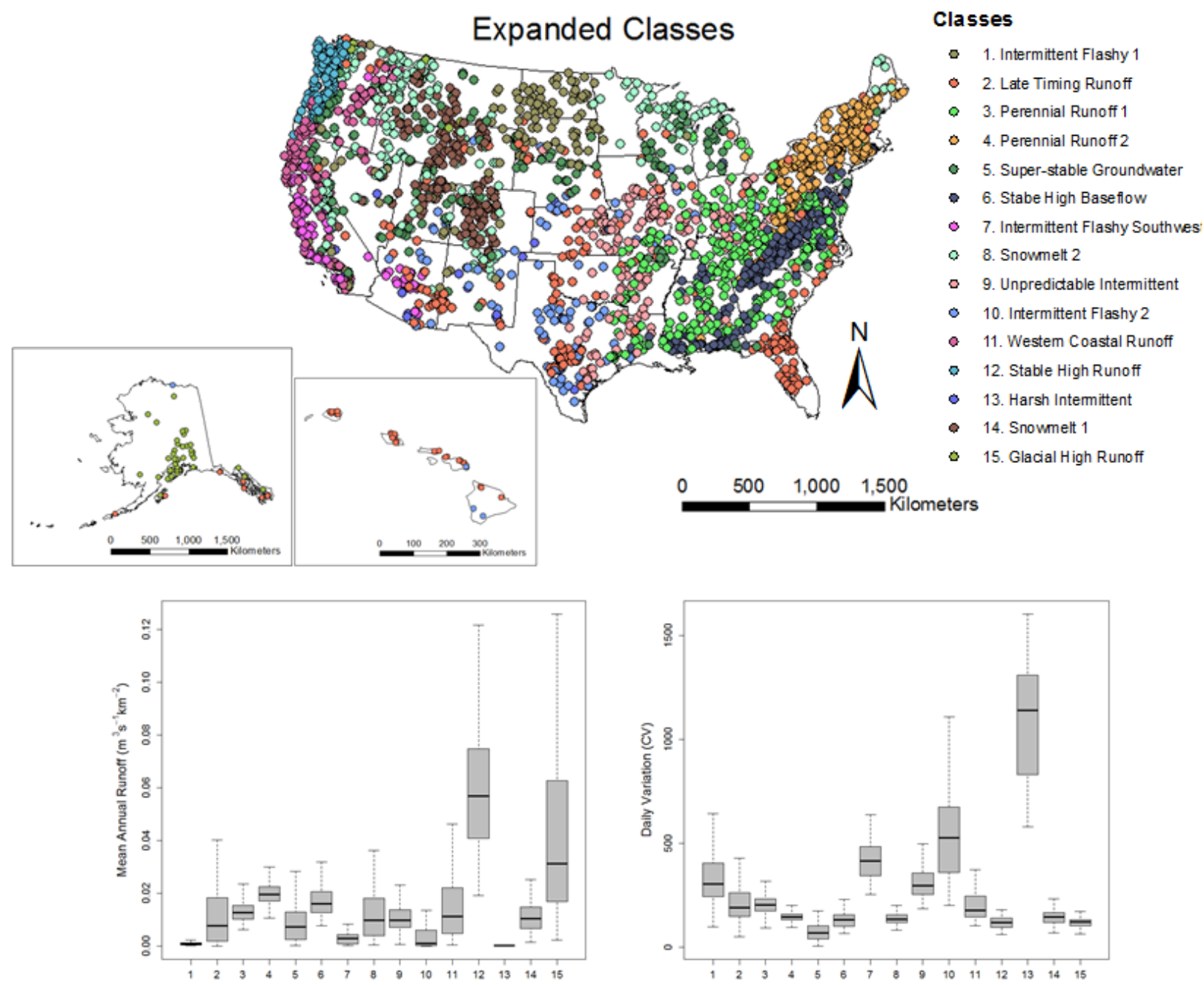

Figure 4. US hydrologic classes ranging from intermittent to highly stable flows. Variables within each class can be represented by a typical range of variation or normal tendency (box and whisker plots). Box and whisker plots represent distribution of mean annual runoff and daily variation according to 15 hydrologic classes. Modified from McManamay et al. (2013b).

In order to provide templates for developing and testing ecologically relevant hypotheses, classification systems created using environmental variables must be linked to ecological patterns. Associations between the U.S. hydrologic classification and fish traits were developed in order to form a template for generating flow-ecology hypotheses and supporting environmental flow standard development (Figure 5). Developing linkages between hydrology and fish assemblages is advantageous for three main reasons. First, many studies have shown that flow variability organizes fish assemblage structure (e.g. Poff and Allan 1995; Jackson et al. 2001; Herbert et al. 2003; Pyron and Lauer 2004). Secondly, spatially contiguous distributions for all freshwater fish species were readily available for the 
conterminous US (NatureServe 2004), thereby providing an effective means to apply a multi-regional hydrologic classification to entire fish assemblages. Lastly, trait information (ecological, life history, behavioral, physiological adaptations to the environment) for the majority of freshwater fish species in North American was also available (Frimpong and Angermeier 2009). Tradeoffs in adaptive strategies for fish (reproductive and life history traits) were observed across a spectrum of stable, perennial flow to unstable intermittent flow, which suggests that fish traits vary predictably along hydrologic gradients (Figure 5). In accordance with theory, periodic strategists were associated with stable, predictable flow whereas opportunistic strategists were more affiliated with intermittent, variable flows (Winemiller and Rose 1992; Winemiller 1995). Linkages between the uniqueness of hydrologic character and ecological distinction among classes were developed, which may translate into predictions between losses in hydrologic uniqueness and ecological community response.

\section{Eco-Class Linkage}
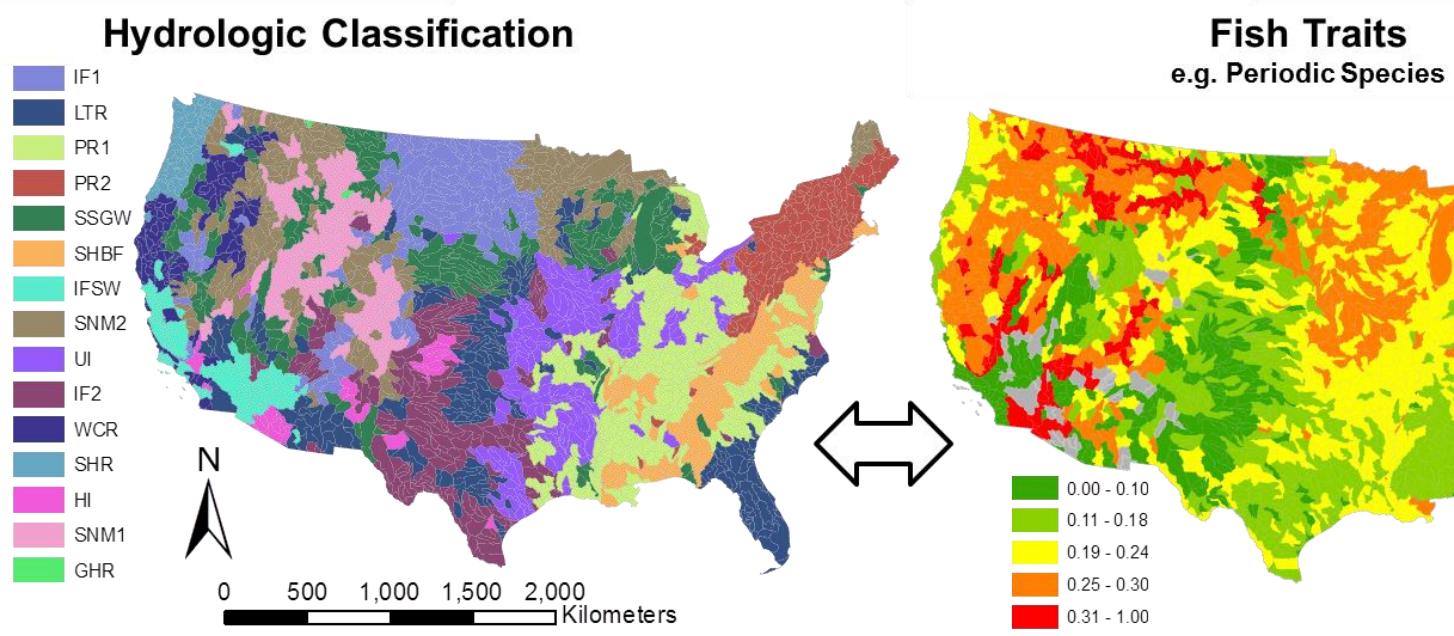

Fish Traits
e.g. Periodic Species
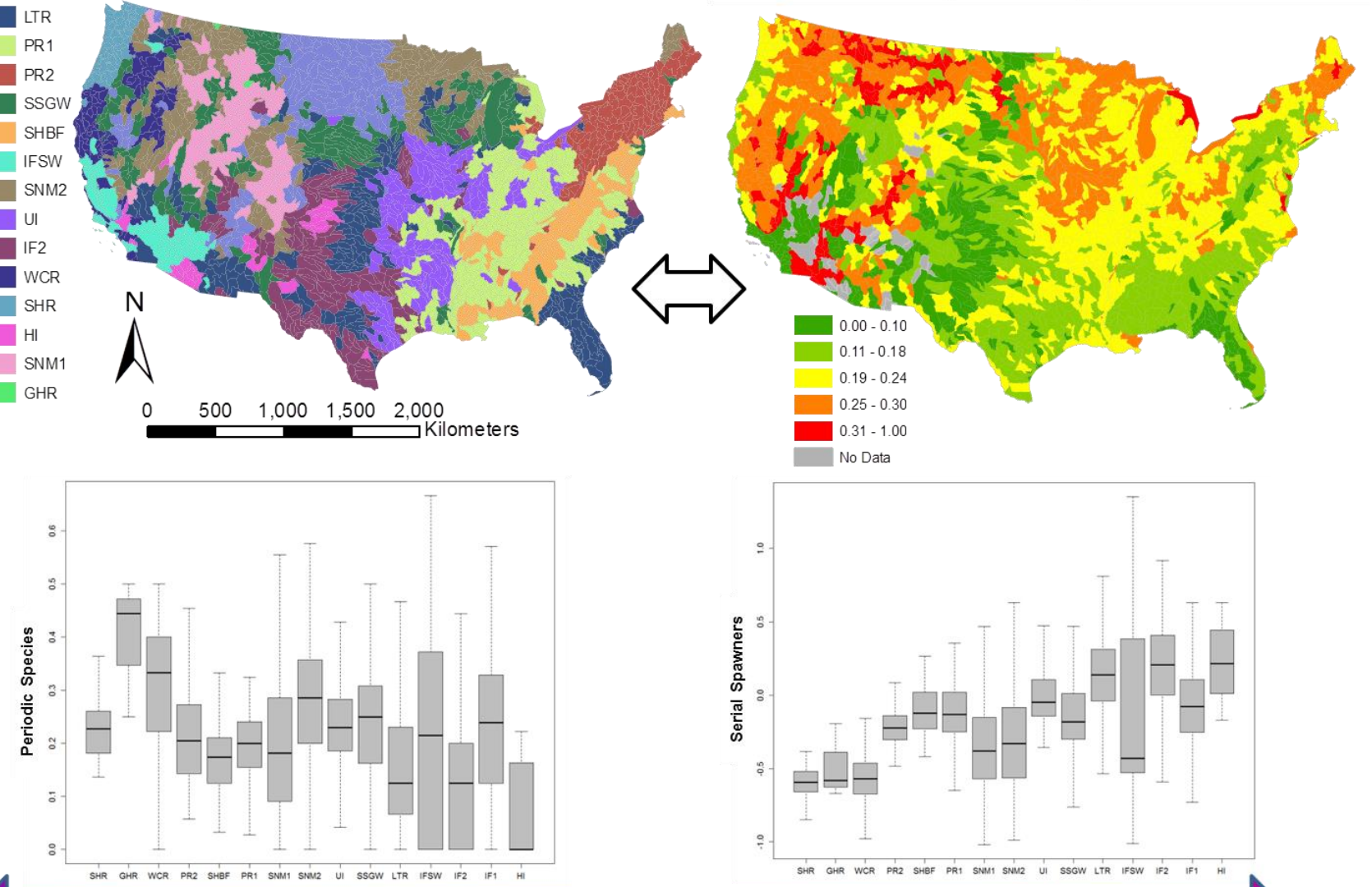

High Runoff

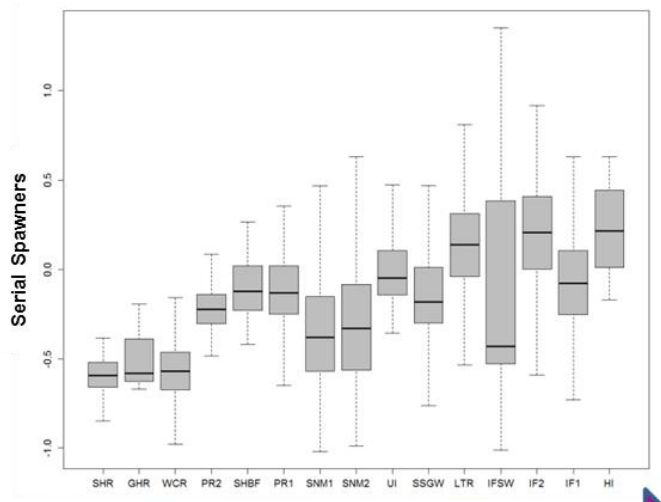

Intermittency

Figure 5. Developing a predictive linkage between the hydrologic classification and fish traits applied to 8-digit hydrologic unit codes (top). Box and whisker plots of distributions of traits (proportion of periodic species, left, and serial spawning index, right) within hydrologic classes. Hydrologic classes were sorted from high runoff to highly intermittent. Modified from McManamay et al. (2013a). 


\subsubsection{Watershed Geomorphic Classes (D)}

Although geomorphic (stream channel morphology) responses to dam-altered flow have been widely studied (Ligon et al. 1995; Grant et al. 2003; Gordon et al. 2004), broad frameworks for assessing channel responses to dams are not as prevalent as flow. Most likely, this is due to unique individual needs for specific river systems, but also to a lack of comprehensive datasets needed to create a geomorphic classification data layer (compared to discharge information used to create hydrologic classes). Grant et al. (2003) created a conceptual and quantitative framework for assessing the effect of dams on morphology; however, application of the framework still depends on local site knowledge. Providing a geomorphic context for hydropower operations is also very important as the existing ecological community and ecological responses to changes in flow may be highly dependent upon channel morphology and underlying geology. For example, within the same physiographic province, a low-gradient gravel-bed river will have far different channel responses to dam-altered flow than a highgradient boulder-dominated river system, despite similarities in hydrology. Coarse classifications, such as the presence of constrained/unconstrained floodplains or the ability of streams to migrate may increase the predictive accuracy of assessing ecological responses to flow variation (Liermann et al. 2011, McCargo and Peterson 2010).

Datasets have become increasingly available to address the potential geomorphic character of hydropower locations at the national scale (Figure 6). Geomorphic classification frameworks could easily incorporate hierarchical structure to provide applications at the landscape, watershed, or reach scale (Figure 6). As an example, the range of sediment/bedload transport within geomorphic classes could provide a normal tendency.

\subsubsection{Dam Operations (D)}

The way in which dams harness water for energy has implications for energy production, project economics, and downstream hydrology. Dams that operate in a run-of-river mode (i.e. harnessing energy soley based on incoming flows) will likely have far less influence on hydrology than those that operate in a peaking mode (i.e. storing and releasing water to generate during peak demand). In reality, dam operations do not fall neatly into one of these two broader categories, but represent a spectrum of operations. Rather than characterizing the mode of operation on a project-by-project basis, a national classification that groups projects by similarities in operational context can already provide a great deal of information concerning context but also provides insight into assessments.

Two different sources were used to determine mode of operation for hydropower dams: 1) FERC orders issuing new licenses for hydropower projects, and 2) internet sources and associated documentation for US Army Corps of Engineers (USACE), US Bureau of Reclamation (USBOR), or Tennessee Valley Authority (TVA) developments. FERC elibrary searches were conducted to compile orders issuing new licenses. Within each order, project operation and facilities descriptions were reviewed to obtain information on mode of operation. Each project may contain multiple dams and associated powerhouses (Figure 7). 
Overall, 232 FERC orders and multiple internet sites for federal projects were reviewed. In total, documentation for 432 power plants was searched and revealed a continuum of seven operation modes from run-of-river (ROR) to strictly peaking (Table 1). Each mode-of-operation type, frequency of power plants in each type, range in megawatt generation capacity, and descriptions are provided in Table 1. The majority of power plants operate as ROR or peaking facilities (Table 1). Approximately 50\% of power plants are non-integral to the dam, i.e. they harness energy from water being diverted from the dam to the powerhouse and bypassing the natural river channel (special note: bypassed reaches vary considerably in length, e.g. meters to kilometers). Operation types were subjectively ranked in order from those with the least hypothetical flow impacts to those with the greatest hypothetical impacts. Thus, based on the definitions for classes given in Table 1, ROR operations should cause the least amount of alteration in daily and subdaily flows relative to peaking and storage release facilities (Table 1). However, operations that involve diversions create another level of impacts to environmental flows as they typically dewater bypassed channels leading to losses in flow volume (Figure 7).

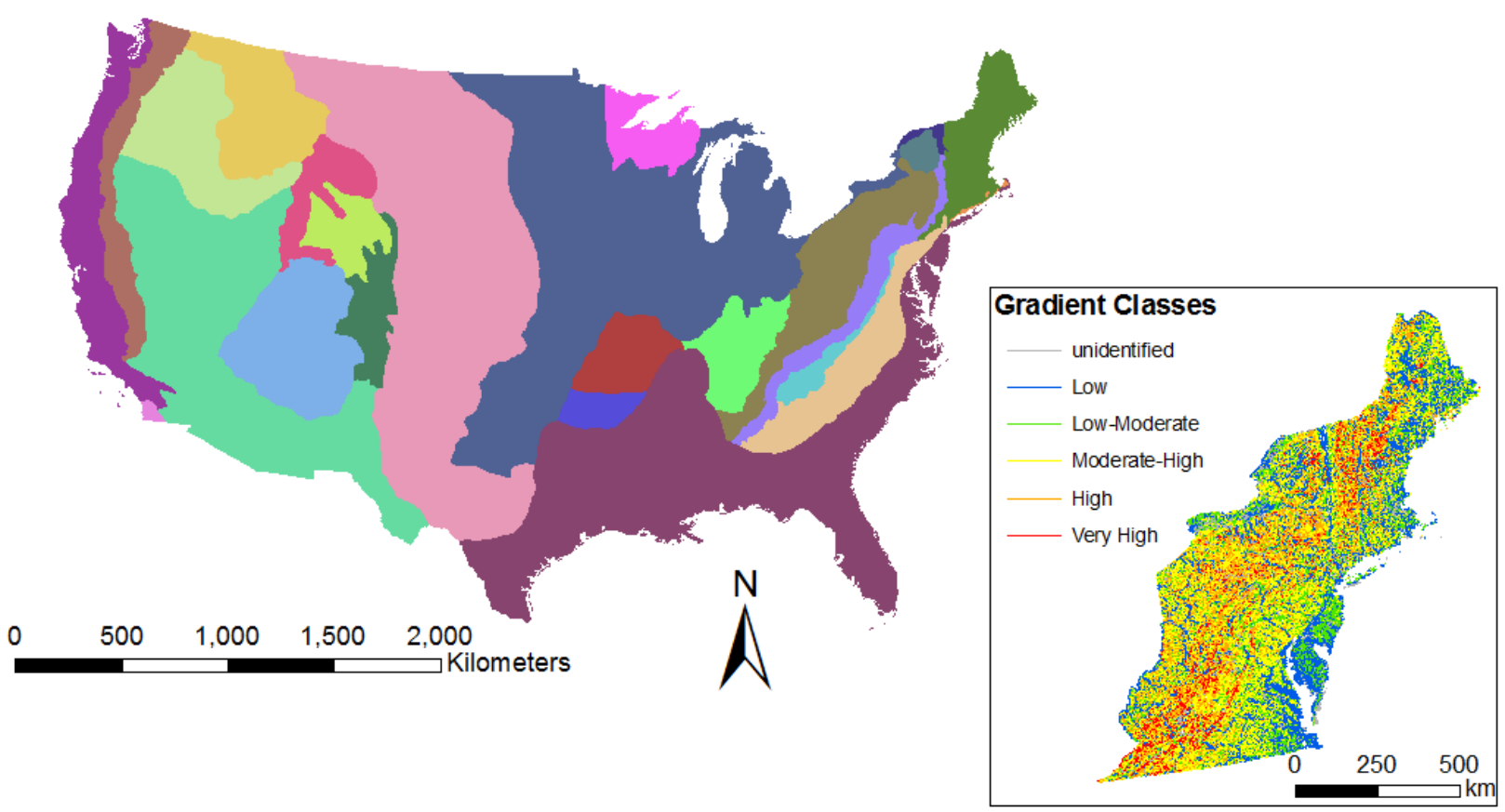

Figure 6. Physiographic provinces across the US that could be used in a geomorphic classification. (Inset) An example of a stream-reach gradient classification conducted for the North Eastern US (data from WMI 2012). 
Table 1. Mode-of-operation classes are listed along with the frequency of 432 power plants surveyed within each class, the range in generation capacity in megawatts (MW), and the description of each class. Generation capacity is the capacity of a facility to generate electricity given the flow volume, hydraulic head, and number and type of generator-turbine units.

\begin{tabular}{|c|c|c|c|}
\hline $\begin{array}{l}\text { Mode-of-Operation } \\
\text { Class }\end{array}$ & $\begin{array}{l}\text { No. of } \\
\text { Power } \\
\text { Plants }\end{array}$ & $\begin{array}{c}\text { MW } \\
\text { Capacity } \\
\text { Range }\end{array}$ & Description/Purpose \\
\hline Run-of-river & 154 & $0.01-436$ & $\begin{array}{l}\text { Discharges from the project tailrace or dam } \\
\text { approximate the sum of inflows to the project } \\
\text { reservoir at any given time. Hydroelectric } \\
\text { generation is dependent upon natural incoming } \\
\text { flows. Minimize the fluctuation of the } \\
\text { reservoir surface elevation. }\end{array}$ \\
\hline Reregulating & 11 & $0.70-49.0$ & $\begin{array}{l}\text { Stores and releases water to stabilize flow } \\
\text { fluctuations from upstream peaking or storage } \\
\text { release facilities and generates electricity. } \\
\text { Mitigation facility. }\end{array}$ \\
\hline Run-of-river/Peaking & 23 & $0.08-28.8$ & $\begin{array}{l}\text { Operates as run-of-river for periods of time or } \\
\text { seasons (e.g. during fish spawning) and then } \\
\text { operates as a peaking facility the remainder of } \\
\text { time. }\end{array}$ \\
\hline Reregulating/Peaking & 1 & 9.6 & $\begin{array}{l}\text { Operates as reregulating facility for periods of } \\
\text { time or seasons (e.g. during fish spawning) and } \\
\text { then operates as a peaking facility the } \\
\text { remainder of time. }\end{array}$ \\
\hline Intermediate Peaking & 42 & $0.10-6809$ & $\begin{array}{l}\text { Stores limited amounts of water for occasional } \\
\text { releases or moderates the intensity of peaking } \\
\text { for hydroelectric generation. }\end{array}$ \\
\hline $\begin{array}{l}\text { Run-of- } \\
\text { river/Upstream } \\
\text { Peaking }\end{array}$ & 48 & $0.68-162$ & $\begin{array}{l}\text { Operates as a run-of-river facility but harnesses } \\
\text { the energy from upstream storage releases or } \\
\text { peaking operations to generate electricity. }\end{array}$ \\
\hline Peaking & 153 & $0.46-912$ & $\begin{array}{l}\text { Stores and releases water (high flow releases) } \\
\text { for hydroelectric generation. Typically large } \\
\text { reservoir fluctuations due to seasonal } \\
\text { drawdowns. }\end{array}$ \\
\hline $\begin{array}{l}\text { Total Number of } \\
\text { dams }\end{array}$ & 432 & & \\
\hline
\end{tabular}




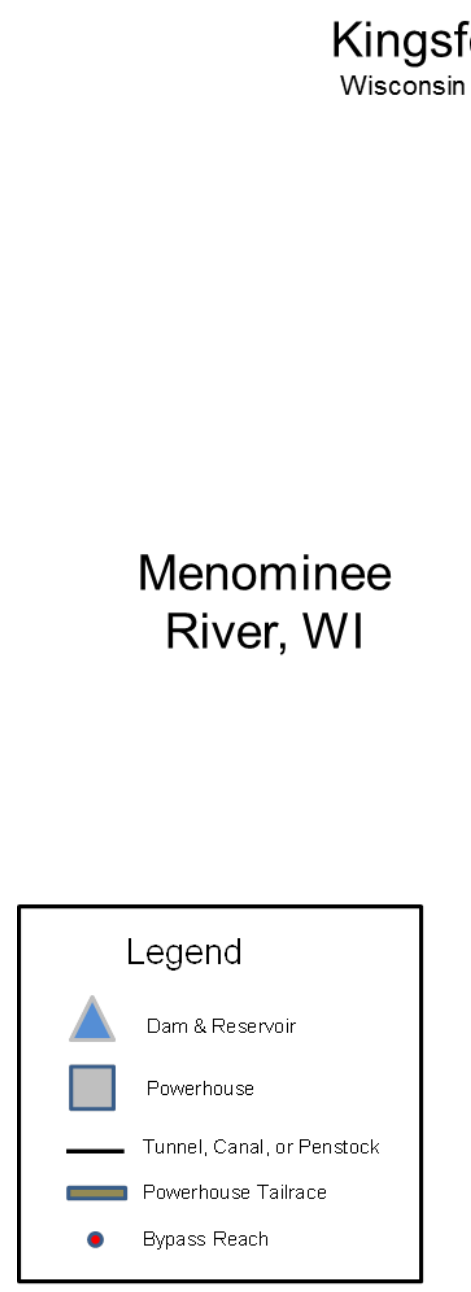

Kingsford Project

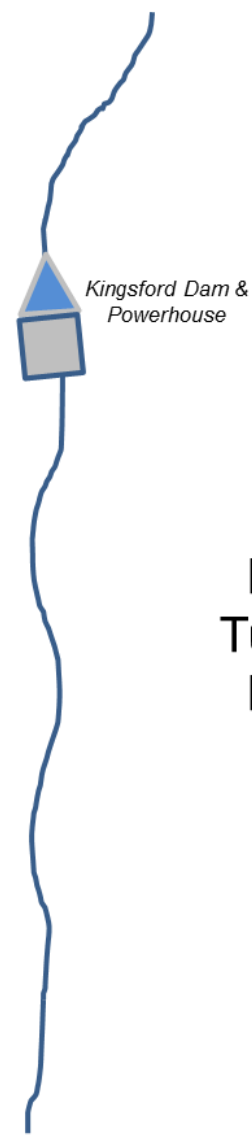

East Fork Project

Duke Energy Carolinas, LLC

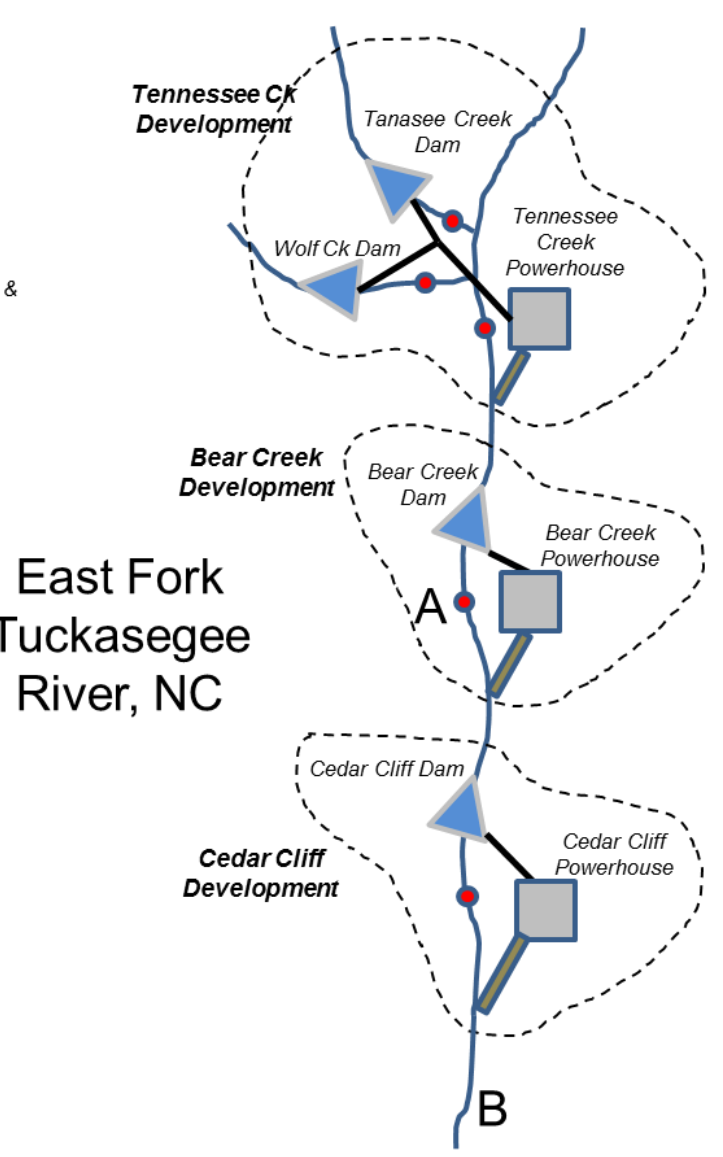

Figure 7. Example of a simple hydropower project containing single dam and powerhouse (Kingsford Project) and a complex project containing multiple developments, dams within a development, and separate structures for dams and powerhouses (East Fork Project). Reaches A and B experience extremely different flows despite being located within the same project. Reach A refers to the bypass channel (flow-diverted reach) below Bear Creek Dam characterized by extreme low flow volumes. Reach B is located below the Cedar Cliff Powerhouse tailrace and receives high flow pulses.

\section{$2.2 \quad$ Assessment}

Management strategies for addressing issues of flow alterations focus on getting stakeholders to examine metrics of flow variability between unaltered and altered conditions in order to determine environmental flow recommendations to support concurrent human and natural uses of rivers. The first step involves the quantification of flow variability (both altered and unaltered conditions), and currently a few widely-used tools are available to provide these assessments. However, another need is to address 
the current ecological condition e.g., does the system support high biodiversity or a recreationally valuable sportfishery? The contextual databases inform this process by providing the groundwork to make comparisons among projects that operate similarly and between projects, affected streams, and their unregulated counterparts. Assessing a project's hydrologic and ecological condition is essential to eventually developing predictable relationships between flow and ecology.

\subsubsection{Daily-Seasonal Flow Statistics (T)}

Currently the most commonly used approaches for quantifying flow variability are based on statistical analyses of daily-averaged flow records like the metrics computed by the Indicators of Hydrologic Alteration (IHA) or Hydrologic Index Tool (HIT) software packages (Richter et al. 1996, Henriksen et al. 2006). Again, this process typically ignores sub-daily hydrologic metrics.

\subsubsection{Sub-daily Flow Statistics (T)}

Hydropower peaking operations have the potential to alter downstream flows above natural variations that occur over the course of a day, which are not captured by flow metrics based on dailyaveraged statistics. The majority of available contemporary tools to assess hydrology utilize daily data to provide daily and seasonal hydrologic metrics (Richter et al. 1996, Olden and Poff 2003). Sub-daily flow metrics and tools to calculate them have seen far less attention (Zimmerman et al. 2010; Meile et al. 2011). In order to fully address the impacts of hydropower operations with respect to naturally occurring flow variability, it is necessary to quantify flow metrics at the sub-daily scale. Additionally, it is important to evaluate sub-daily flow metrics with respect to their ability to correlate with changes in downstream geomorphic processes and biologic responses that occur over a wide-range of temporal and spatial scales. Although the hydrologic classification was created using daily and seasonal metrics, sub-daily metrics provide a finer scale context related to dam operations and specific ecological responses. Bevelhimer et al. (2013) summarized several sub-daily statistics that can be used to assess hydrology related to hydropower projects (Table 2, Appendix).

\subsubsection{Hydrologic condition (D)}

Assessing hydrologic alterations is critical to understanding where a project sits in the spectrum of natural to artificial environments. An unbiased assessment considers both types of environments equally suitable as long as they both meet social and ecological demands. The hydrologic condition of a project can be conceptualized as a tri-point continuum, which provides a baseline for moving towards idealized conditions depending on ecological objectives (Figure 8). A project may modify the timing and distribution of flows without large losses to annual water budget (endpoint B, Figure 8). However, diversions reduce the water budget thereby limiting the quantity and quality of habitat (endpoint $\mathrm{C}$, Figure 8). Both daily/seasonal and sub-daily flow metrics can be utilized to capture a project's hydrologic condition.

McManamay et al. (2013b) developed an approach to determine hydrologic condition in damregulated gages based on hydrologic class membership. In short, the approach consisted of 1) assigning dam-regulated gages to appropriate hydrologic classes based on class predictive models, 2) using multivariate measures to assess deviation from the 'normal tendency' of hydrologic class, and 3 ) and 
determining outliers (river systems outside the normal tendency). Dam-regulated streams (1,180 gages) were assigned to one of the expanded hydrologic classes using the class predictive model (Figure 9). Postdam construction hydrologic data for each regulated gage was obtained and daily statistics were calculated. Mahalanobis distances (multivariate distance measure) were calculated between each regulated gage and the centroid of the unregulated gages within each hydrologic class. Outliers were detected as breaks (i.e. abnormalities) from the chi-squared distribution of Mahalanobis distances according to Filmoser and Gschwandtner (2012) (Figure 9). The approach can be useful in determining whether regulated streams are functioning within the bounds of the normal tendency.

Table 2. Seven sub-daily flow statistics and their descriptions (from Bevelhimer et al. 2013).

\begin{tabular}{|c|c|c|}
\hline Metric & Full Name & Description \\
\hline Daily CV & $\begin{array}{l}\text { Daily Coefficient of } \\
\text { Variation }\end{array}$ & $\begin{array}{l}\text { The common statistical calculation of standard deviation dividing be } \\
\text { the mean of the } 24 \text { hourly flow values. Like daily range, daily } \\
\text { standard deviation is an indicator of degree of habitat and behavior } \\
\text { change. }\end{array}$ \\
\hline DeltaDaily & Standardized daily delta1 & $\begin{array}{l}\text { A variation of the percent of total flow metric, this metric is calculated } \\
\text { as the daily delta (i.e., difference between minimum and maximum) } \\
\text { divided by the daily mean for each day (adapted from Meille et al. } \\
2011 \text { ). This value is twice the standardized daily range as defined by } \\
\text { Lundquist and Cayan ( } 2002 \text { ) as the ratio of the amplitude (half of } \\
\text { daily range) of the diurnal cycle to total daily discharge over the } \\
\text { analysis period (e.g., } 24 \mathrm{hr} \text { ). }\end{array}$ \\
\hline DeltaAnnual & Standardized daily delta2 & $\begin{array}{l}\text { Same as DeltaDaily except the difference between the daily } \\
\text { minimum and maximum is divided by the mean annual daily flow. }\end{array}$ \\
\hline HrlyRamp & $\begin{array}{l}\text { Standardized maximum } \\
\text { ramp rate }\end{array}$ & $\begin{array}{l}\text { Greatest hourly change in flow during a } 24 \text {-hr period (Halleraker et } \\
\text { al. } 2003 \text {, Meille et al. 2011) divided by the daily mean. }\end{array}$ \\
\hline Reversals & Reversals & $\begin{array}{l}\text { Number of changes between rising and falling periods of the } \\
\text { hydrograph; adapted from similar metric derived with daily data (The } \\
\text { Nature Conservancy 2007). Counting reversals with hourly data can } \\
\text { be a bit misleading since even the slightest change in either direction } \\
\text { could produce a reversal count that is insignificant relative to general } \\
\text { trends in the hydrograph. Therefore, calculation of reversals should } \\
\text { be qualified such that only reversals of a certain minimum magnitude } \\
\text { are counted. For this study we used } 10 \% \text { of each day's mean flow } \\
\text { as the threshold. Computationally this is more challenging but it } \\
\text { provides a better metric. }\end{array}$ \\
\hline RichBak & $\begin{array}{l}\text { Richards-Baker flashiness } \\
\text { index (Baker et al. 2004) }\end{array}$ & $\begin{array}{l}\text { The path length of flow oscillations (sum of the absolute values of } \\
\text { hour-to-hour changes in hourly flows) calculated as the geometric } \\
\text { distance of the daily hydrograph of flow versus time (adapted from } \\
\text { Baker et al. 2004). Daily path length was divided by the daily mean } \\
\text { over each 24-hr period. Higher values indicate greater stream } \\
\text { flashiness or more rapid variation in flow. }\end{array}$ \\
\hline RiseFall & $\begin{array}{l}\text { Difference in rise and fall } \\
\text { counts }\end{array}$ & $\begin{array}{l}\text { Difference between the number of hours of rising and falling flow as } \\
\text { determined with each pair of consecutive flow values. Over a } 24-\mathrm{hr} \\
\text { period, the difference between rise and fall counts can range from } \\
+24 \text { to }-24 \text {. Continuous rising flows throughout a day would produce } \\
\text { a score of }+24 \text {, while all falling flows would produce a score of }-24 \text {; } \\
\text { an equal number of rising and falling counts would produce a score } \\
\text { of } 0 \text {. Over a longer period, the difference between the rise and fall } \\
\text { counts reveals whether flows take longer to rise toward a maximum } \\
\text { or fall toward a minimum. For example, flood flows often take longer } \\
\text { to subside than to rise. }\end{array}$ \\
\hline
\end{tabular}




\section{Hydrologic Condition}

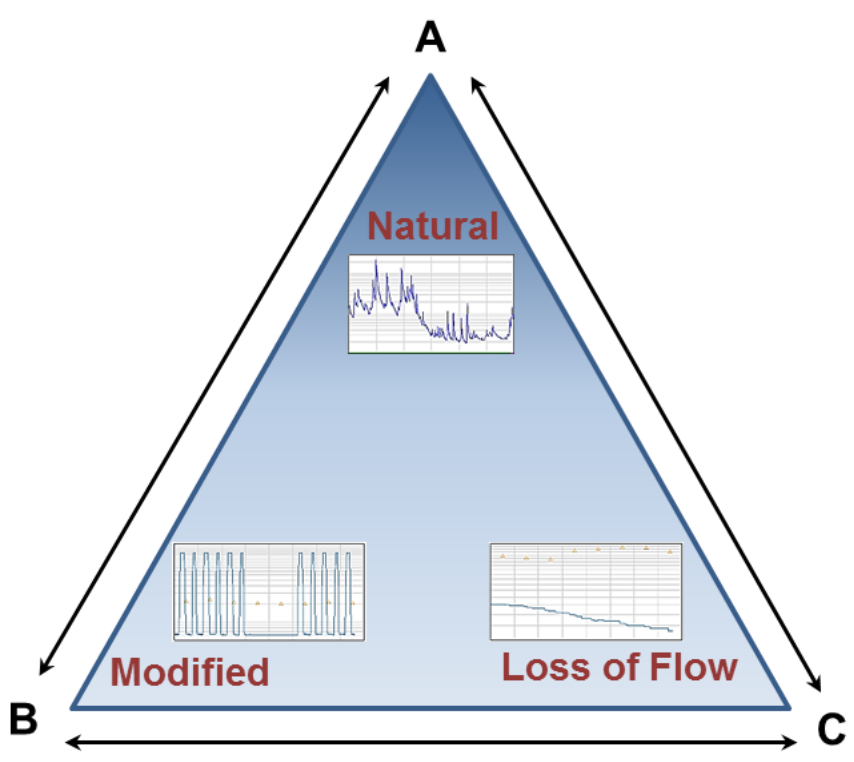

\section{Ecological Condition}

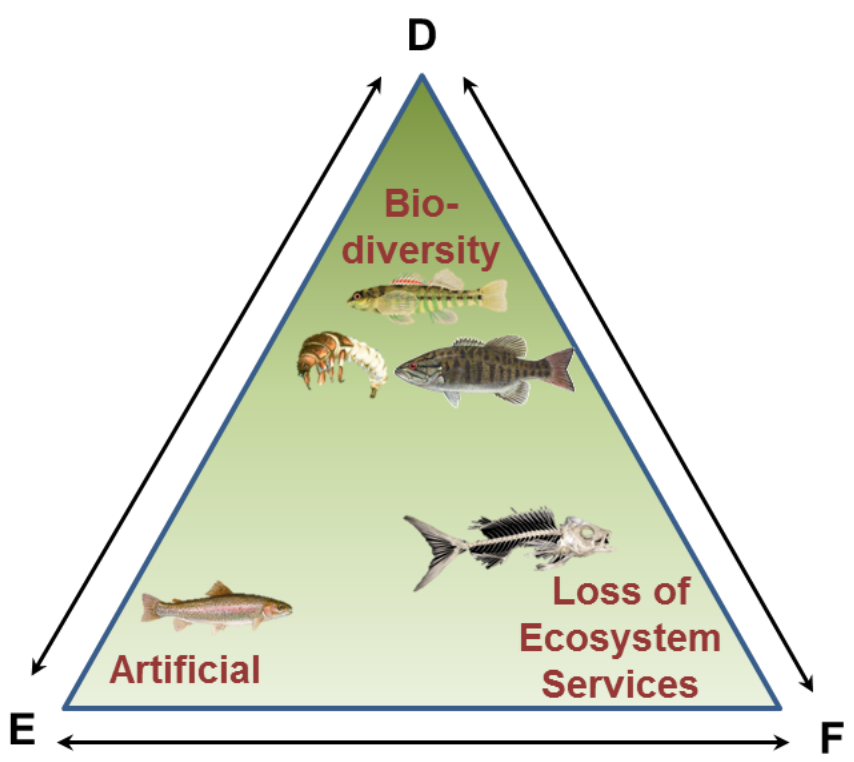

Figure 8. Tri-point continuum of hydrologic and ecological condition for a given hydropower project. A project may (A) have little modification to flow, (B) modify the timing and distribution of flows without large losses to annual water budget, or $(C)$ divert large quantities of water thereby reducing the water budget thereby limiting the quantity and quality of habitat. Likewise a project may (D) have little modification to natural biodiversity, (E) have highly modified river communities that support ecosystem services, such as sportfisheries, or (F) have extensive losses to ecosystem services. Associations among hydrologic and endpoints are likely to exist; however, ecological endpoints should not be viewed as directly related to hydrologic endpoints (e.g. B does not necessarily result in $\mathbf{E}$ ).

Bevelhimer et al. (2013) assessed the hydrologic condition of examples of run-of-river projects and peaking projects compared to natural streams across the U.S. (Figure 10, Appendix). A comparison of sub-daily and daily flow yielded different patterns and suggested that sub-daily statistics may do a better job than daily statistics in illuminating differences among streams regulated by various dam operations (Figure 10, Appendix). Furthermore, the ability to explain generalized ecological responses to damaltered flow may depend upon the widespread use of sub-daily rather than daily statistics.

Assessing hydrologic condition also applies to specific hydropower operations. For example, the hydrologic classification dataset, class predictive models, and daily-seasonal flow statistics were used in concert to analyze the hydrologic condition of the Snake River below Hells Canyon Dam, Idaho (Figure 11). Hells Canyon Dam is owned and operated by Idaho Power Company as a peaking operation. Because Jackson Lake Dam was built in 1911 in the upper mainstem, very little pre-regulation information was available for the lower Snake River. Thus, landscape and climate variables were assembled and used in the class predictive model to predict the appropriate hydrologic class. Based on model predictions, the Snowmelt 2 hydrologic class (class 8) was determined as the appropriate hydrologic type. Unregulated streams within the Snowmelt 2 class provide a typical range of variation. A random subset of gages $(n=6)$ from the Snowmelt 2 class was selected and $\sim 20$ years of hydrologic data 
were obtained for each gage (Figure 11). For each year, each average daily discharge was divided by the maximum daily discharge for that year in order to standardize flow information from gages of varying contributing basin sizes.

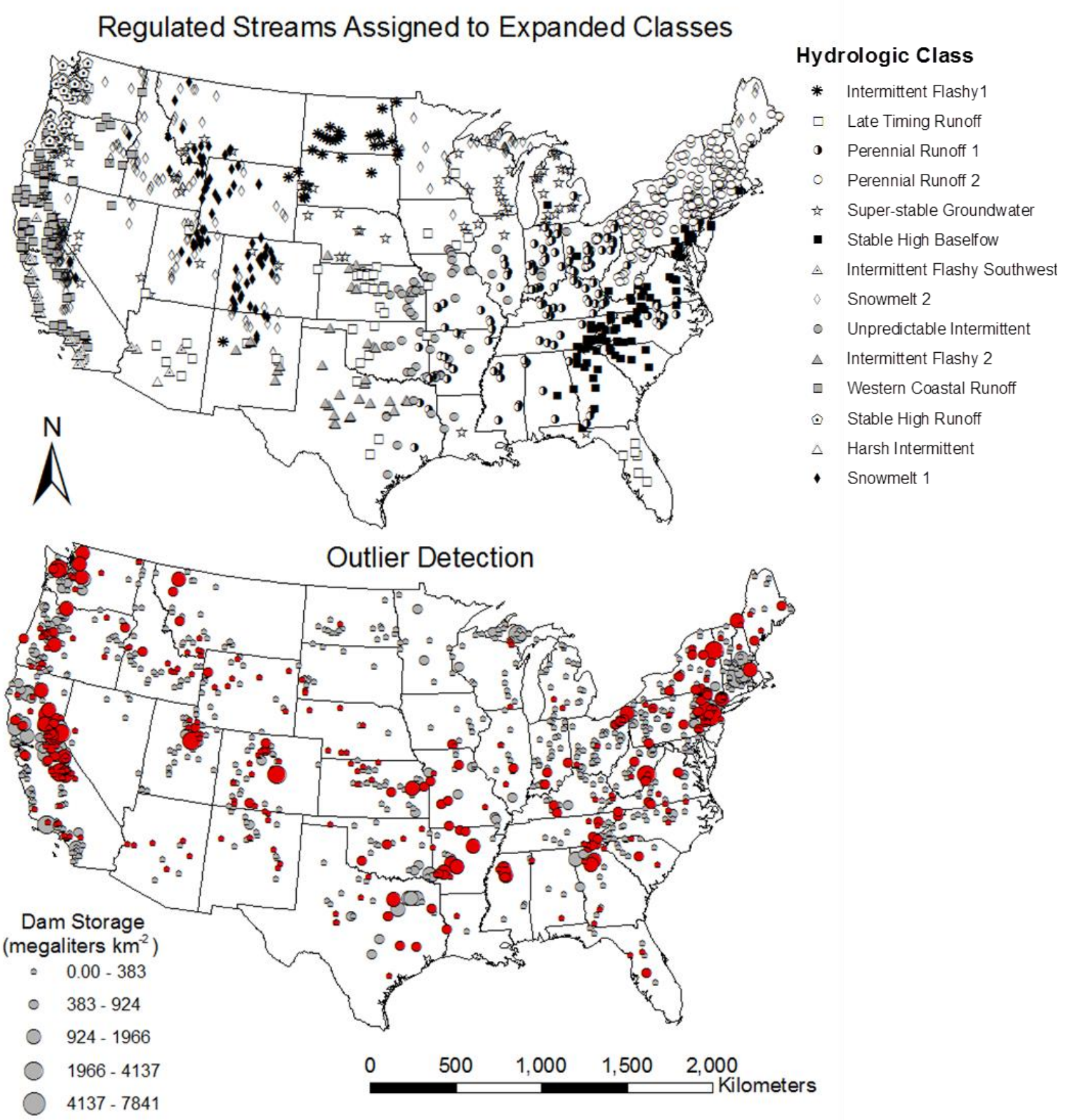

Figure 9. Dam-regulated stream gages $(n=1,180)$ assigned to hydrologic classes using the classpredictive model (top). Outliers (red dots) detected using Mahalanobis distances calculated between each regulated gage and the centroid of the unregulated gages within each hydrologic class (bottom). The size of the dots represent the total upstream dam storage above each gage corrected for drainage area. From McManamay et al. (2013b). 

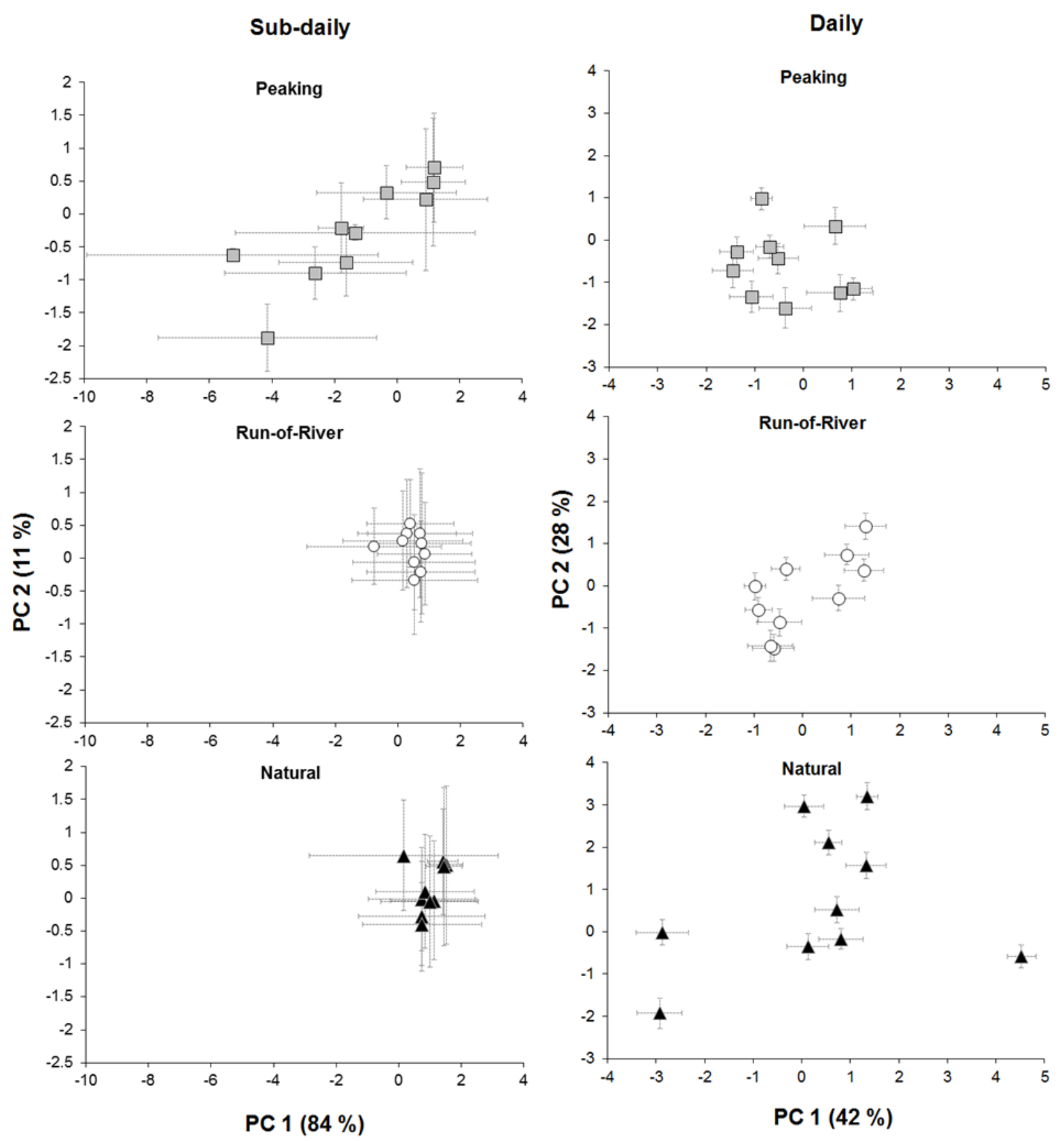

Figure 10. A comparison of hydrologic conditions for peaking and run-of-river hydropower projects assessed using sub-daily or daily statistics. The comparison yielded opposing results for subdaily and daily statistics. Sub-daily statistics yield more consistent results than daily statistics when assessing hydrologic conditions among operations. From Bevelhimer et al. (2013). 


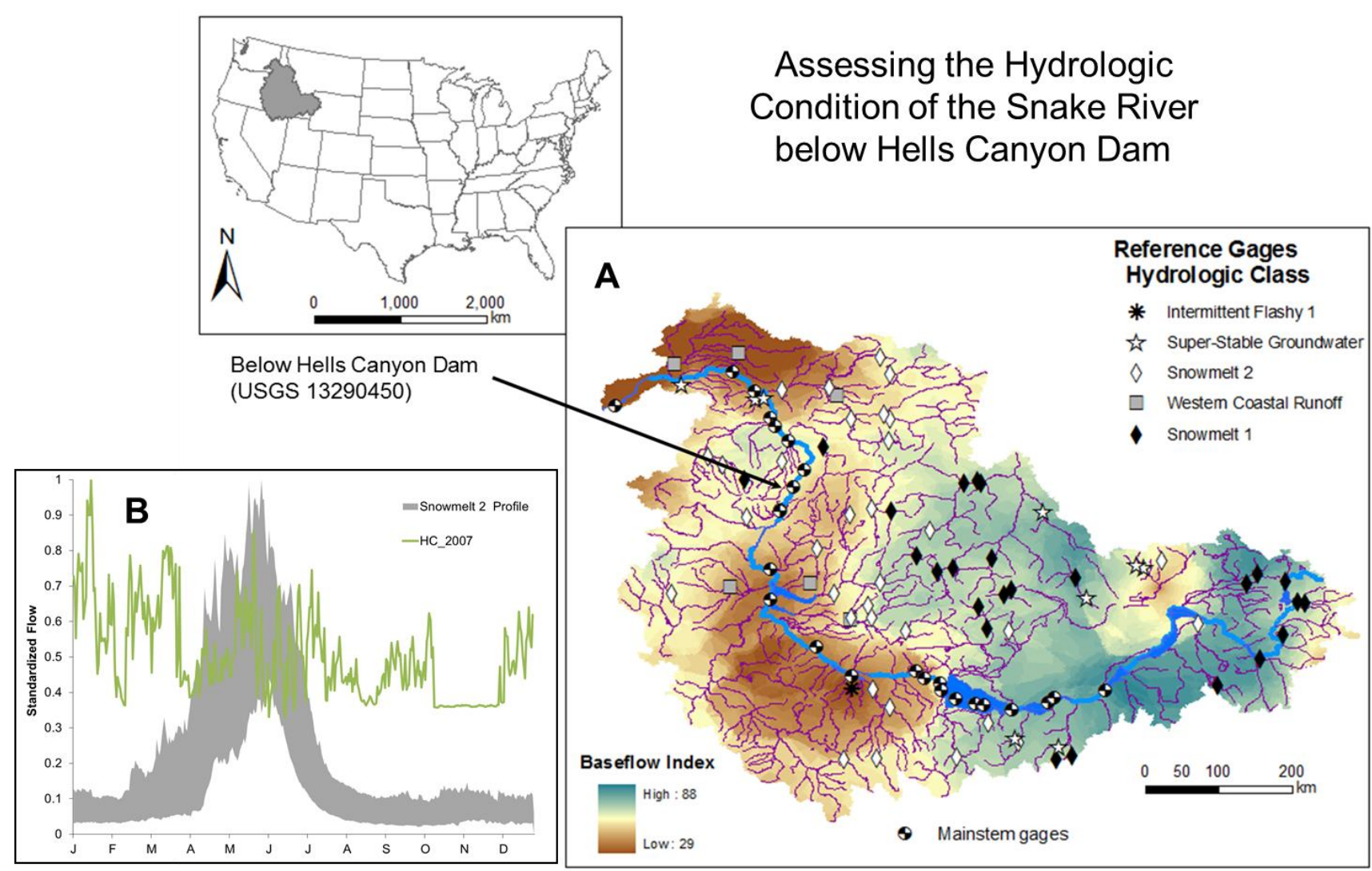

Figure 11. An assessment of the hydrologic condition of the Snake River below Hells Canyon Dam, Idaho. (A) Using class prediction models, USGS gage 13290450 was classified as a Snowmelt 2 type stream. (B) Comparisons of the current flow below Hells Canyon Dam to the Snowmelt 2 hydrologic profile $\left(10^{\text {th }}\right.$ to $95^{\text {th }}$ percentile of standardized flows) reveal departures from the relative magnitude of annual maxima and seasonal baseflows. Standardized flow calculated by dividing each year by maximum flow.

By combining over 100 gage-years of hydrologic information, a hydrological class profile could be developed for the Snowmelt 2 class (Figure 11). The hydrologic class profile represents the $10^{\text {th }}$ to $95^{\text {th }}$ percentile range of variation of standardized flow for each day of the year. Discharge data from the Hells Canyon gage (USGS 13290450) was standardized in a similar fashion. A comparison on hydrologic profiles very quickly reveals departures from the relative magnitude of annual maxima and seasonal baseflows (Figure 11).

Hydrologic classes provide a template to assess departures from the normal tendency. Although the normal tendency represents the natural flow regime, it is not meant to override or place an agenda on specific flow objectives. However, understanding departures from normal tendencies provides a relative comparison of where project operations fit into a larger picture. The inter-quartile-range (IQR) of a particular hydrologic metric represents the central tendency within a hydrologic class and a quantitative approach to measuring hydrologic alteration (Figure 12). Using hydrologic classes as a measure of central tendency is advantageous for a number of reasons. First, as mentioned previously, pre-dam regulation information may not be available. Second, hydrologic classes represent a range of values rather than a single metric - thereby providing a measure of uncertainty. Lastly, magnitude-related 
metrics within hydrologic classes can be standardized by the median daily flow value as to remove the effect of river size and diversions. Because of substantial irrigation withdrawals within the Snake River Basin, standardized flow metrics provide a robust method to evaluate the relative magnitude of seasonal variation (Figure 12). Comparing flows below Hells Canyon Dam to the full magnitude of expected flows would result in less useful results since the full historic magnitude is not available for improving ecological conditions. Again, this suggests that using baseline information to inform hydropower operations may be misleading. In contrast, assessing hydrologic alterations based on the magnitude of available flows produces more realistic options.

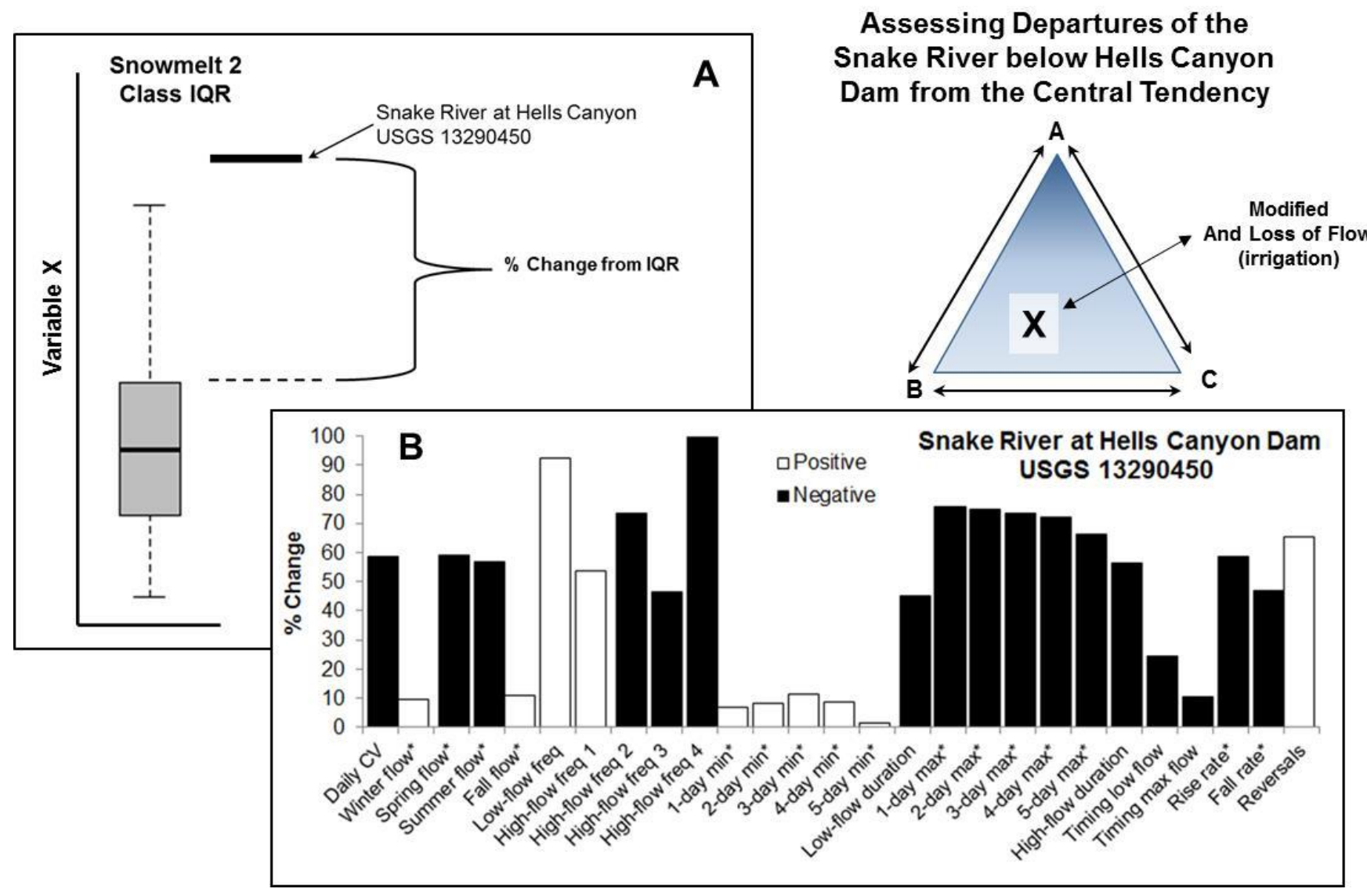

Figure 12. (A) Assessing departures in a given variable for the Snake River below Hells Canyon Dam from the central tendency represented as the inter-quartile range for the Snowmelt 2 Class (gray section of box and whisker plot represent interquartile range (IQR) whereas error bars represent $95^{\text {th }}$ percent confidence interval). (B) Percent changes of USGS 13290450 from the IQR of the Snowmelt 2 class for 27 daily flow statistics.

* indicates that the statistic was standardized by mean daily flow.

As a similar example, the hydrologic classification dataset, class predictive models, and hydrologic statistics were used to evaluate changes in hydrologic conditions for the Brule River following a FERC relicensing agreement for Brule River Dam (Figure 13). Historically, Wisconsin Electric Power 
Co. operated Brule River Dam (built 1919) in a peaking mode until 1995 when the company switched to operating the project as run-of-river. A series of sub-daily statistics were also calculated and compared with daily statistics between the two periods (Haas et al. 2013, Appendex). Based on the predictive model, there was a 50-50\% chance that the Brule River could either be classified Snowmelt 2 stream (class 8) or a Super-stable Groundwater stream (class 5). The hydrologic record for the Brule River gage (USGS 04062011) was split into two periods: pre- and post-FERC relicensing (1989-1995 and 19962013, respectively). Daily statistics were calculated for each period. For reference, Snowmelt 2 and Super-stable Groundwater streams within a $100-\mathrm{km}$ radius were selected and daily statistics were calculated. Standardized daily flow statistics for each period were compared to the central tendency found within the reference gage classes (Figure 13). Again, these results can rapidly assess the hydrologic condition of a given hydropower project.

\subsubsection{Ecological Geospatial Data (T)}

Multiple geospatial datasets providing local and regional ecological datasets have become increasingly available (Figure 14A). A very simple yet advantageous tool would provide quick access to biological information from basins neighboring a hydropower project. Building ecological datasets at finer resolutions will require statistical modeling to accurately represent the composition of river communities (Figure 14B-C).

\subsubsection{Ecological condition (D)}

The ecological condition of a hydropower project provides an indication of hydrologic, as well as general environmental conditions. For example, if a fish community below a hydropower facility in the southeastern U.S. is dominated by warm-water-intolerant species, then this suggests a likely hypolimnetic release from the dam regardless of the hydrologic condition. Hence, in some ways, the ecological condition provides as much context as it does assessment. Similar to hydrologic conditions, the ecological condition can also be conceptualized within a tri-point continuum (Figure 8). Eco-class linkages can provide a range of variation representative of a given hydrologic class. As a coarse approach, linkages between the uniqueness of hydrologic character and ecological distinction can be used to predict associations between hydrologic change and ecological community response. For higher resolution analyses, utilizing geospatial tools can provide more accurate distributions of species. A comparison of fish assemblages below a hydropower project to that of local sites within the same hydrologic class can provide a rapid assessment of shifts in community structure as well as missing species. 
Assessing the Hydrologic Condition of the Brule River Project: Pre and Post FERC Relicensing

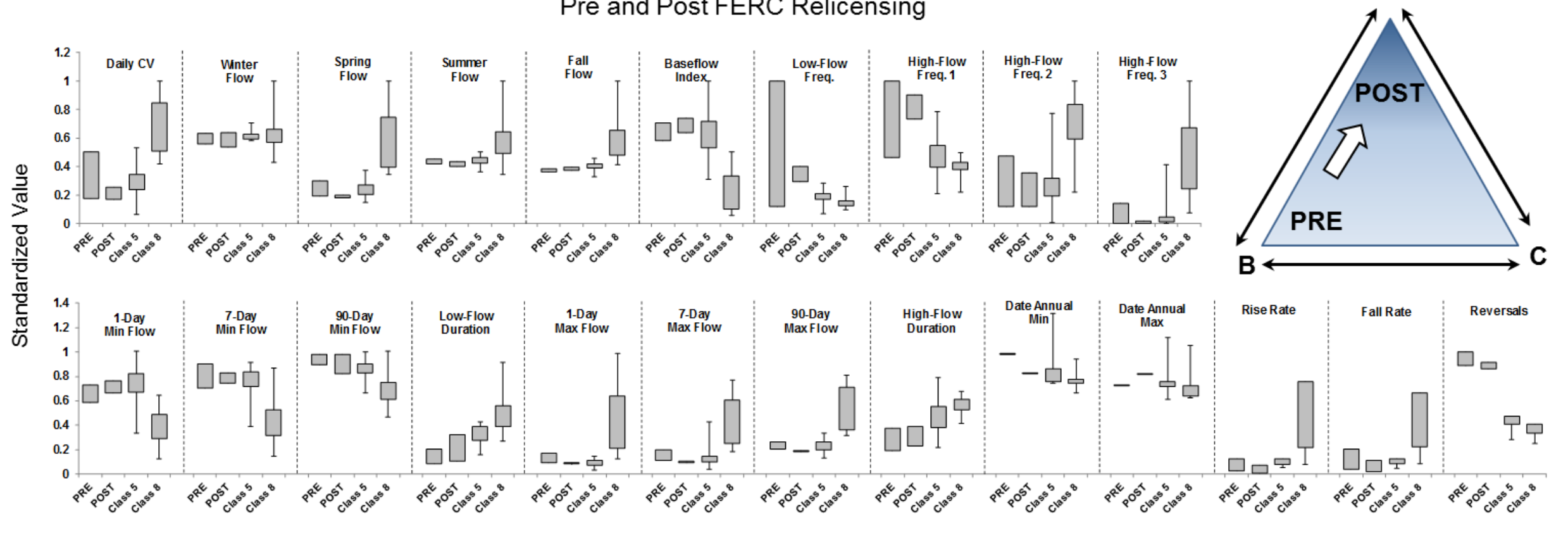

Figure 13. Comparison of the Brule River for peaking conditions (Pre-relicensing, 1989-1995) and run-of-river conditions (Postrelicensing, 1996-2013) with respect to the interquartile ranges of 23 daily hydrologic statistics represented by the Super-stable Groundwater Class (Class 5) and the Snowmelt 2 Class (Class 8). Although the predictive model suggested shared membership between Class 5 and 8, results of the hydrologic condition assessment suggest that Class 5 is more appropriate. Large changes in most hydrologic variables from pre- to post- relicensing were not observed. However, for evidence changes post-relicensing, hydrologic conditions were more similar to the normal tendency represented by Class 5 . 

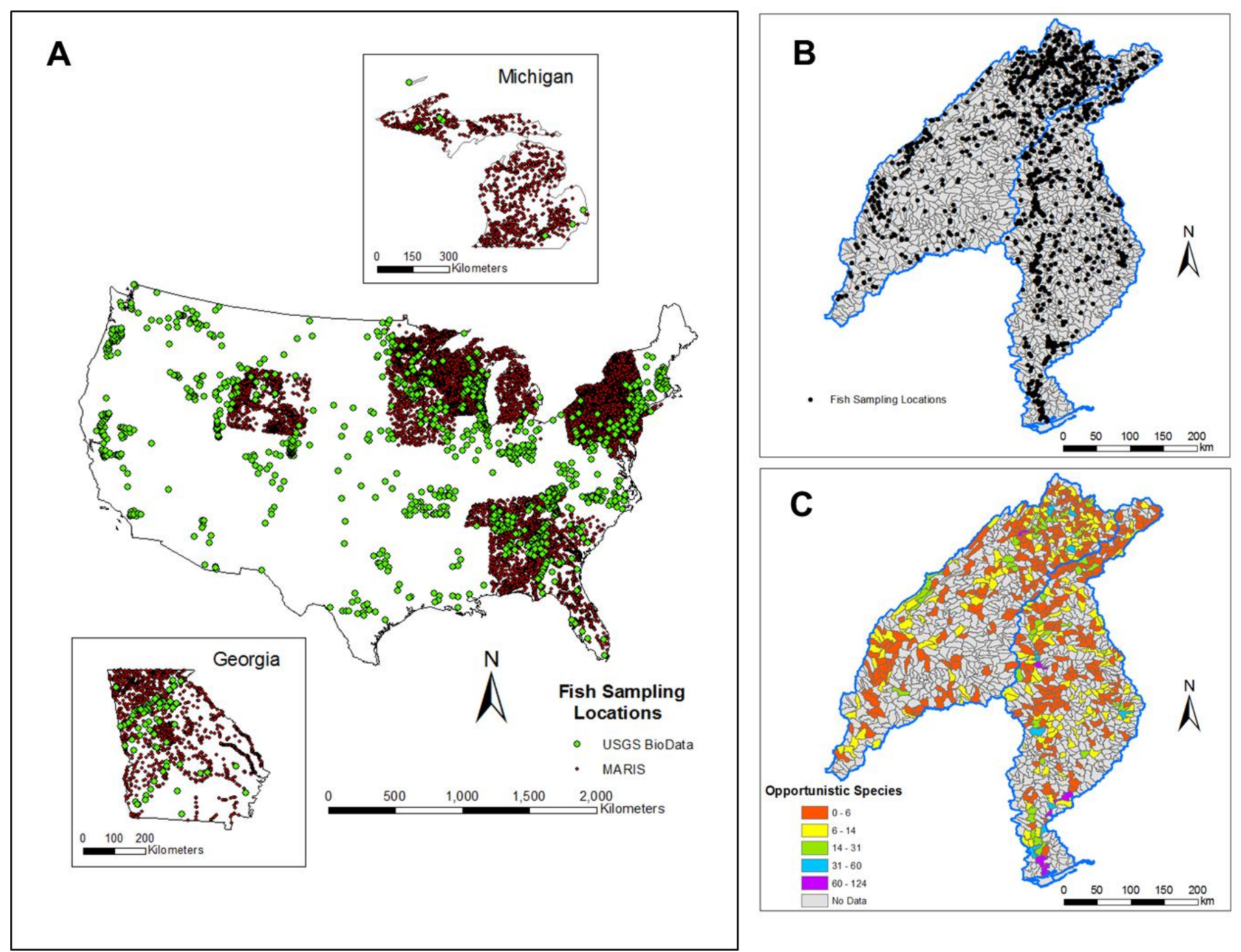

Figure 14. Examples of ecological geospatial data sets. (A) Fish sampling point locations provided by two data sources for the U.S.. (B) Multiple sources can be combined to create composite datasets for regions, such as fish sampling locations within the Appalachicola-Flint and Alabama Coosa Tallapoosa River basins. (C) Combined datasets can be summarized to create localized ecological layers to support assessing hydropower project ecological condition. 


\section{$2.3 \quad$ Scoping}

Context and assessment represent conventional datasets and tools that inform the remainder of the environmental flow determination process, regardless of the hydropower situation. Scoping, prescription, and feasibility elements, however, require stakeholder inputs as they are individual to each hydropower project. For example, the scoping process requires stakeholders to identify ecological objectives specific to each project. Based on the individualistic needs, the previous elements and tools can be used to isolate and prioritize information gaps, a reduced set of key hydrologic metrics, and predictive relationships between proposed flow changes and ecological response. A major part of the scoping process is identifying studies that will inform the impact of current and future operations and aid in determining environmental flows; thus, substantial time and cost savings can benefit from information amassed prior to the scoping process.

\subsubsection{Ecological Targets (D)}

Successful environmental protection or restoration depends on developing appropriate goals and considering the context of each management situation (Roni et al. 2002); however, appropriate goals must be substantiated by establishing measurable objectives (Tear et al. 2005). Based on the current and desired ecological conditions, stakeholders must identify measurable objectives or ecological targets, such as increases in native fish richness, increases in sportfish biomass, or increases in the frequency and duration of floodplain inundation. The basis for each ecological target can be substantiated by the information provided in the context and assessment.

\subsubsection{Eco-Evidence Tools (T)}

Many novel approaches are now available to assist in environmental flow decision making, which require developing predictable relationships between changes in flow and ecological responses. For example, Norris et al. (2012) developed a form of causal criteria analysis, called Eco Evidence, which uses published literature to support a priori developed cause-effect hypotheses. For example, if increasing salmonid spawning success was selected as an ecological target, an example hypotheses might be as follows: decreasing daily flow fluctuations (range in flows) will increase salmonid redd success. Extensive reviews of the stream flow and ecology literature and associated database compilation can provide support for hypotheses, but also quantitative predictions at the regional scale. For example, McManamay et al. (2013d) developed a literature review, compiled a database, and conducted a quantitative meta-analysis of ecological responses to changes in flow in the South Atlantic region of the U.S. (Figure 15). The approach can yield quantitative and directional relationships between changes in flow and ecological responses (Figure 15). These relationships can help guide the development of recommended environmental flows.

Geospatial analyses can also provide regional quantitative/predictive flow-ecology relationships to inform the scoping element. Mims et al. (2013) used paired fish sampling data from river locations below dams and in nearby unregulated locations to form quantitative relationships between changes in flow variation and fish assemblages. Geospatial analyses can harness the context and assessment data layers to generate quantitative flow-ecology relationships. 
1. Develop Literature Review Library

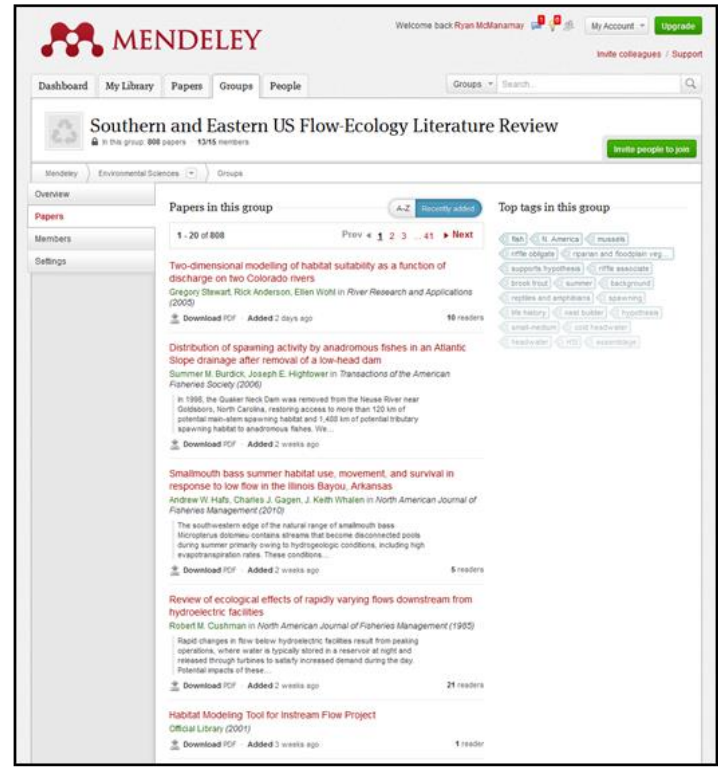

4. Extract Quantitative Flow-Eco Relationships

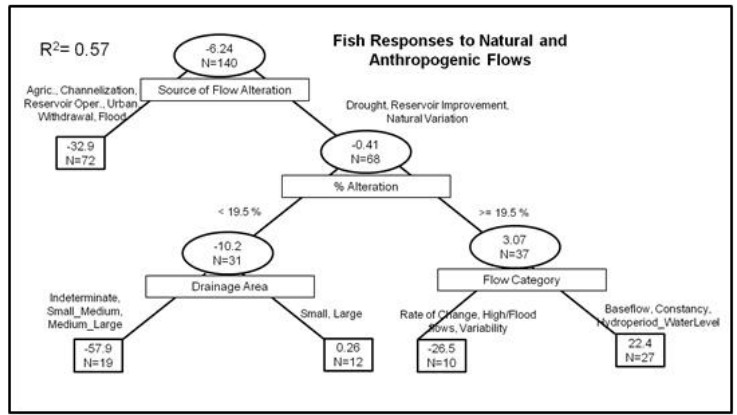

2. Assemble Work Group

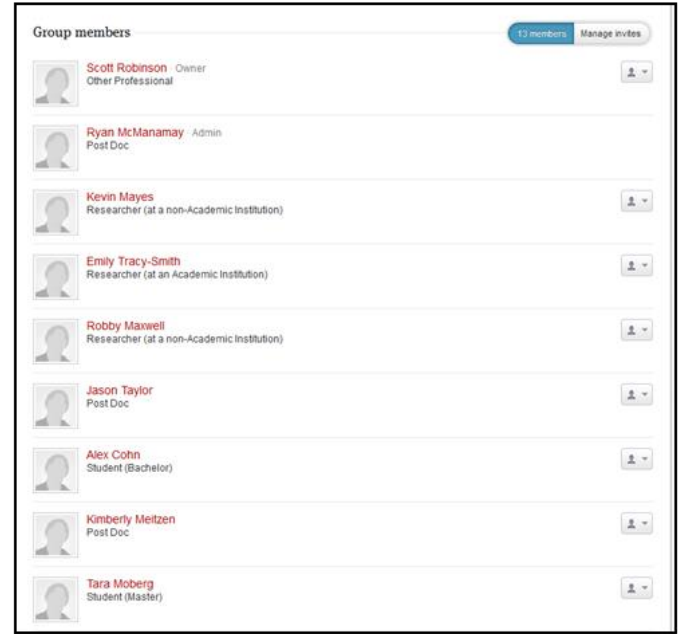

3. Construct Eco-Evidence Database

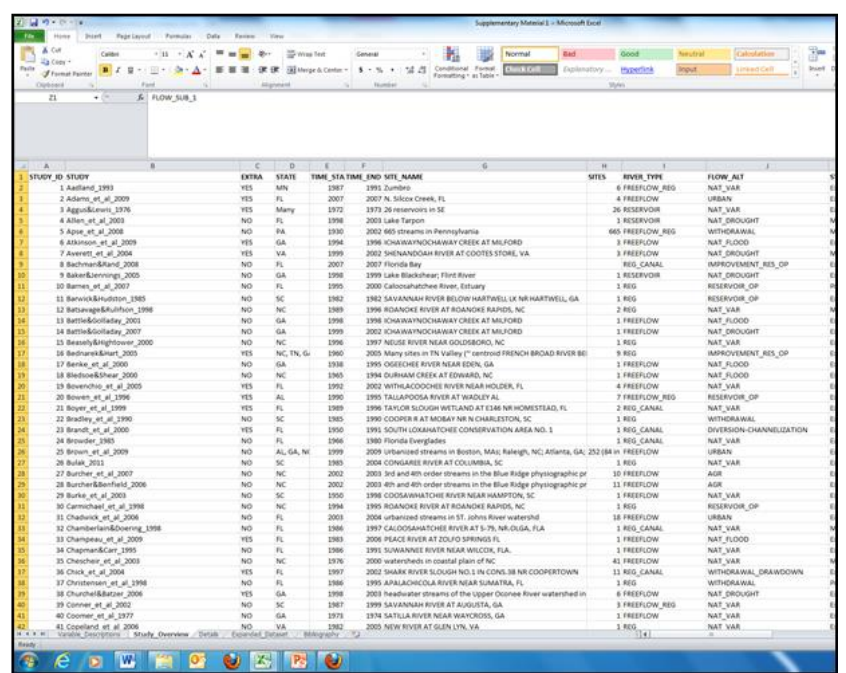

Figure 15. An example of an Eco-Evidence approach (modified from McManamay et al. 2013d). Based on literature compilation, work groups can develop databases representing a regional knowledge base. The database can be used to extract flow-ecology relationships, develop predicted responses to flow restoration, or isolate key hydrologic/ecological indicators for a specific context.

\subsubsection{Key Hydrologic and Ecological Indicators (R)}

Depending on current ecological conditions, identified ecological targets, and predictive relationships (eco-evidence toolbox), the scoping process can yield a subset of hydrologic and ecological indicators to inform the flow prescription and feasibility elements. Ideally, ecological indicators are predictably linked to hydrologic indicators through quantitative relationships. The previous application steps yield the data and framework required to create predictive flow-ecology relationships. For example, McManamay et al. (2013c) compiled/collected hydrologic information, fish assemblage information, and riparian information for regulated and unregulated streams falling within the Stable High Baseflow class 
within the Upper Tennessee Basin (Figure 16). After constructing multivariate models to control for habitat fragmentation, gradient, and elevation, predictive relationships between flow and ecology (fish richness/riparian cover) were developed (Figure 16). Relationships developed for flow classes and regions could guide the scoping process by identifying key hydrologic and ecological indicators and their relationships with each other. These relationships can guide the prescription of alternative flow scenarios.

\subsubsection{Identify Information Gaps (R)}

Identifying key indicators outlines the objectives for environmental flows. However, all the information required to generate predictable linkages between each hydrologic indicator and ecological responses for each individual hydropower context is unlikely. Thus, the scoping process can identify gaps in knowledge and thereby, solidify relicensing studies to fill those gaps. Collaborative and interdisciplinary workshops can be used to fill in the missing information gaps (Richter et al. 2006).

\section{$2.4 \quad$ Prescription}

Prescribing environmental flow alternatives should not be confused with the outcome of a FERC order. In contrast, the prescription of potential alternative flow scenarios should come well within the licensing process. These prescriptions should be evaluated and tested in feasibility analyses (section 2.5).

\subsubsection{Alternative Flow Scenarios (D)}

Alternative flow prescriptions (e.g. Table 3) should be developed using the available knowledge base (Context, Assessment, Scoping processes) with the intent of filling information gaps. Thus, prescription is also a stakeholder led process that utilizes best available science to identify a spectrum of scenarios of varying risk for hydropower and environmental stakeholders. Multiple alternative flow scenarios can be developed that address key hydrologic indicators identified in the scoping process.

\section{$2.5 \quad$ Feasibility Analysis}

Developing alternative flow scenarios and assessing those scenarios through monitoring has been conducted in very few settings (e.g. Krause et al. 2005; Richter et al. 2006). For example, environmental flow recommendations for the Savannah River below Thurmond Dam (USACE) were developed through a collaborative process, implemented on a trial basis, and then monitored to make adaptive adjustments (Richter et al. 2006). Modeling approaches, such as flow optimization and habitat simulation techniques, provide an assessment of the feasibility of alternative flows prior to implementation. Models can aid in determining whether ecological outcomes can be achieved in light of existing constraints. For example, stakeholders may desire alternative flows that compromise power generation required to support local economies. Other constraints may include factors outside the realm of control by project operations, such as substantial losses in total flow due to irrigation requirements, structural limits to providing optimal conditions, or limiting habitat factors (e.g. channel morphology, habitat connectively, water quality). 

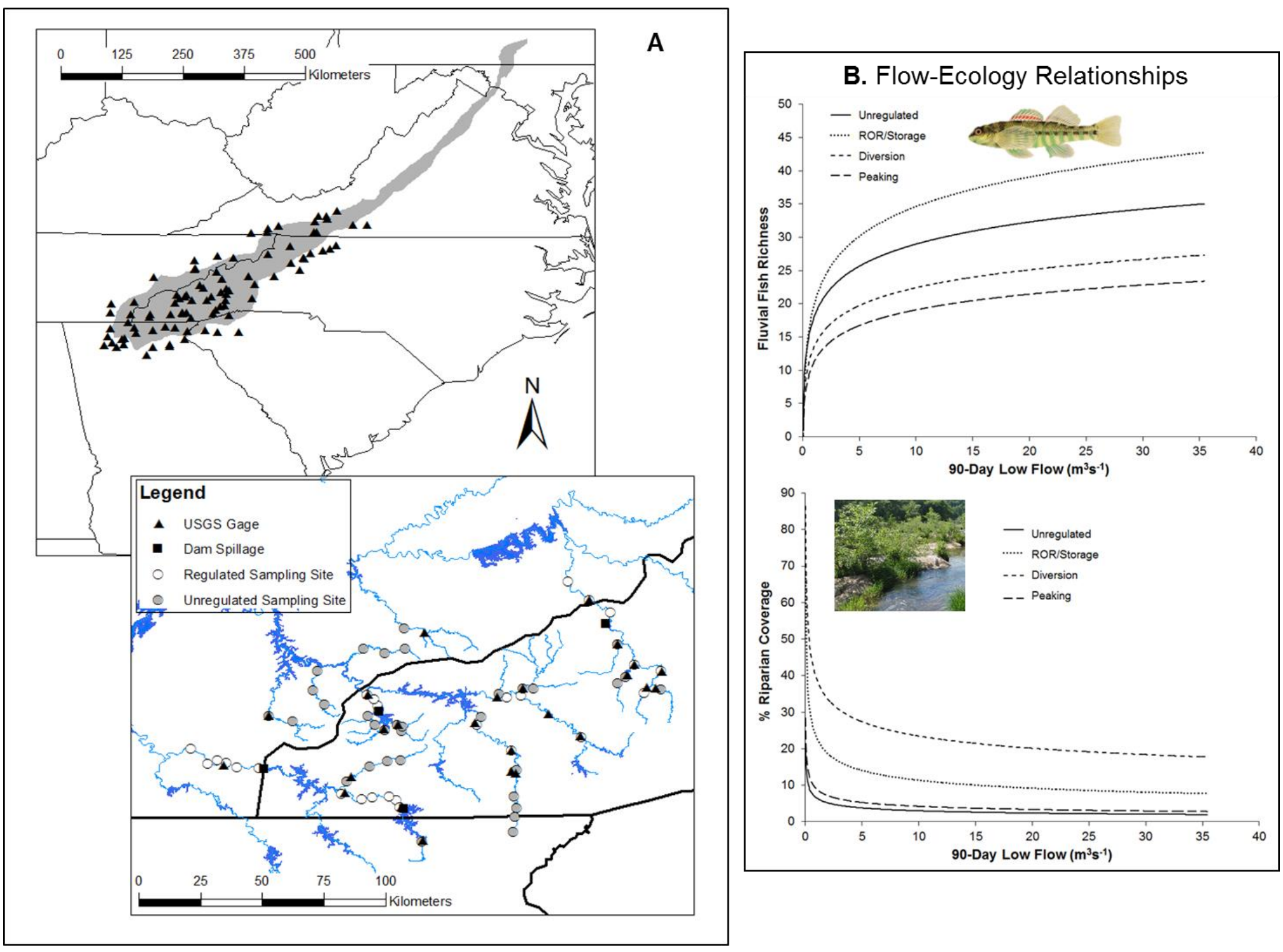

Figure 16. (A) Compilation of regional hydrologic information (USGS gages and dam spillage) and fish sampling locations for the Upper Tennessee River Basin. (B) Based on multivariate models, simulations can yield predictive flow-ecology relationships to predict fish richness or riparian vegetation responses to changes in flow. Modified from McManamay et al. (2013c). 
Table 3. Examples of alternative flow scenario components to be tested during feasibility studies. Alternative scenarios can represent one to many different flows within each component and/or one to many different combinations of components.

\begin{tabular}{|c|c|c|}
\hline $\begin{array}{l}\text { Flow Scenario } \\
\text { Component }\end{array}$ & Description & Potential Ecological/Societal Benefit \\
\hline \multicolumn{3}{|l|}{ Baseflow } \\
\hline Minimum flow & $\begin{array}{l}\text { Constant baseflow supplied year- } \\
\text { round between generation. }\end{array}$ & $\begin{array}{l}\text { Entire channel perimeter remains inundated and } \\
\text { reduces fish stranding following generation. } \\
\text { Creates more stable environment. }\end{array}$ \\
\hline $\begin{array}{l}\text { Seasonally variable } \\
\text { baseflow }\end{array}$ & $\begin{array}{l}\text { Baseflow magnitude varies } \\
\text { according to season. }\end{array}$ & $\begin{array}{l}\text { Seasonally fluctuating flow provides enhanced } \\
\text { flows during different spawning times for fish and } \\
\text { habitat refugia to support varying life stages of } \\
\text { macroinvertebrates and riparian vegetation. }\end{array}$ \\
\hline \multicolumn{3}{|l|}{ Flood Pulses } \\
\hline $\begin{array}{l}\text { Frequent small flood } \\
\text { (rafting release) }\end{array}$ & $\begin{array}{l}\text { Scheduled releases of small flood } \\
\text { events periodically during year ( } 5 \\
\text { to } 10 \text { times) during appropriate } \\
\text { seasons. }\end{array}$ & $\begin{array}{l}\text { Provides channel maintenance such as scouring or } \\
\text { flushing sediment, inundating roots, removing } \\
\text { encroaching vegetation, and redistributing } \\
\text { spawning substrates. Also could provide } \\
\text { recreational boating opportunities. }\end{array}$ \\
\hline $\begin{array}{l}\text { Annual large flood } \\
\text { (riparian pulse) }\end{array}$ & $\begin{array}{l}\text { Scheduled large flood event (per } \\
1.5 \text { years) }\end{array}$ & $\begin{array}{l}\text { Creates new habitats by shifting large amounts of } \\
\text { substrates, provides organic matter inputs from } \\
\text { floodplain, inundates backwater habitats, and } \\
\text { provides nursery habitats for fish. }\end{array}$ \\
\hline \multicolumn{3}{|l|}{ Special-events } \\
\hline Attractant flow & $\begin{array}{l}\text { Pulsed flows attract upstream } \\
\text { migrating fish to ladders }\end{array}$ & $\begin{array}{l}\text { Enhances fish passage, reproduction, and } \\
\text { population viability. }\end{array}$ \\
\hline Passage flow & $\begin{array}{l}\text { Pulsed flows to enhance/protect } \\
\text { outmigration }\end{array}$ & $\begin{array}{l}\text { Enhances fish survival, recruitment, and population } \\
\text { viability. }\end{array}$ \\
\hline \multicolumn{3}{|l|}{ Sub-daily } \\
\hline Ramping restriction & $\begin{array}{l}\text { Restrictions in the rate of change } \\
\text { of the rising limb of generation } \\
\text { pulse }\end{array}$ & $\begin{array}{l}\text { Creates less disturbance by reducing square- } \\
\text { shaped hydrograph. Allows time for behavioral } \\
\text { responses to initiation of peak generation. }\end{array}$ \\
\hline $\begin{array}{l}\text { Down-ramping } \\
\text { restriction }\end{array}$ & $\begin{array}{l}\text { Restrictions in the rate of change } \\
\text { of the falling limb of generation } \\
\text { pulse }\end{array}$ & $\begin{array}{l}\text { Prevents fish stranding by providing time for } \\
\text { behavioral responses to flow recession. }\end{array}$ \\
\hline Daily range restriction & $\begin{array}{l}\text { Restrictions in range of } \mathrm{min} / \mathrm{max} \\
\text { flows during day }\end{array}$ & $\begin{array}{l}\text { Reduces disturbance and creates more stable } \\
\text { environment to enhance feeding and spawning } \\
\text { habitats. }\end{array}$ \\
\hline $\begin{array}{l}\text { Diurnal variation in } \\
\text { generation }\end{array}$ & $\begin{array}{l}\text { Shifiting the timing of generation } \\
\text { within a day }\end{array}$ & $\begin{array}{l}\text { Generating during different times of the day may } \\
\text { provide more temporal overlapp of hydrologic } \\
\text { stability and peak feeding times. }\end{array}$ \\
\hline
\end{tabular}




\subsubsection{Instream Flow Tools (T)}

In section 1.2, multiple environmental flow frameworks were briefly summarized with the majority falling into the category of instream flow tools. In contrast to holistic environmental flow strategies (such as DRIFT, ELOHA, etc), instream flow tools are typically used to assess specific ecological targets under varying flow conditions within a particular reach (e.g. segment of a tailwater). Although they are only applicable to a reach of interest, individual attention is required to provide the most accurate ecological predictions within alternative flow scenarios given that channel morphology, temperature, and habitat connectivity can be dramatically different depending on the hydropower project. The required time and resource commitment vary substantially depending on the instream flow approach taken. These tools can provide variable outputs such as estimated biological habitat, bioenergetic, population, or geomorphic responses.

\subsubsection{Habitat Connectivity (D)}

Obviously, dams lacking passage facilities block the migration and dispersal of organisms among populations and habitats required for various life stages (Vaughn and Taylor 1999; Han et al. 2008; Hoagstrom et al. 2008; Reid et al. 2008). Depending on the context, feasibility analyses should take local colonization, extinction, and meta-population dynamics into account. Environmental flows may be implemented for organisms whose distribution is poorly known. Thus, understanding the distribution of various species may help determine whether migratory potential is inhibited by physical barriers or poor habitat quality inducing barrier-type effects. Implementing environmental flows to support species recolonization without assessing the ability of species to colonize is a poor management practice.

\subsubsection{Reach Geomorphic Classes (D)}

Local channel depth, channel complexity, and substrate conditions interact with flow to determine the habitat template for a particular organism. Reach or habitat classifications become advantageous in stratifying locations for instream flow studies, assessing the presence/absence of species, and prioritizing areas for morphological restoration. For example, Vernon et al. (2013) developed a geomorphic classification framework in conjunction with a two-dimensional hydraulic model to assess optimal juvenile salmonid rearing habitat under varying flow regimes in the lower Snake River Basin. Reachscale geomorphic classifications can increase the predictive accuracy of flow-habitat models and provide a template to assess alternative mitigation strategies. For example, the output from the geomorphic classification and two-dimensional hydraulic model (Vernon et al. 2013) can be used to determine the feasibility of flow restoration compared to morphological restoration. Specifically, gravel addition may provide more ecological benefits than flow restoration. Restoring bedload transport and spawning habitats below impoundments through gravel and sediment augmentation has been documented largely in salmonid rivers in the western U.S. (Kondolf et al. 1996; Merz and Setka 2004; Merz and Chan 2005; Sarriquet et al. 2007) and to a lesser extent in the eastern U.S. (McManamay et al. 2010). Bunte (2004) provides a detailed guide to gravel mitigation and augmentation below dams and provides a conceptual framework in determining the amount, location, and timing of gravel additions. 


\subsubsection{Water Quality (D)}

The standard protocol for IFIM includes modeling temperature with variable discharge releases (Bovee et al. 1998; Krause et al. 2005). However, according to Olden and Naiman (2010) incorporating thermal regimes into environmental flow assessments is rarely done. They indicate that some of the challenges of incorporating assessments of thermal regimes into flow assessments are due to a lack of understanding of the impact of dams on temperature, the ecological consequences of an altered temperature, and limited knowledge of the availability and success of temperature management strategies. Releases from stratified layers of an impoundment can result in water quality regimes drastically different from natural conditions and may constrain or complicate the ecological benefits of environmental flows (Pozo et al. 1997; Hamblin and McAdam 2003; Lessard and Hayes 2003; Krause et al. 2005; Olden and Naiman 2010). Price and Meyer (1992) provide a guide to operational and structural water quality management techniques for reservoirs and tailwaters.

Water quality conditions may pose such stringent constraints on tailwater conditions, that alternative flow scenarios provide little ecological benefit. Thus, water quality modeling should be included in feasibility analyses. For example, Krause et al. (2005) simulated temperature scenarios using a hydrodynamic model coupled with temperature modeling to assess the influence of various flow releases on the thermal regime below a hypolimnetic-release hydropower dam in Virginia. Despite 15 different alternative flow-scenarios, stream temperatures remained well-below suitable growth thresholds for brown trout. Likewise, Bevelhimer et al. (1997) modeled temperature responses to proposed management alternatives for the Madison River below Madison Dam. Interestingly, model results suggested that none of the proposed alternatives was likely to produce a significant decrease in water temperature. Conversely, restoration of the river to natural flow conditions would have actually caused downstream temperatures to be higher thereby negatively impacting a blue-ribbon trout fishery. Sherman (2000) provides a review of various temperature mitigation strategies considering dam structure and the use of stratification layers to mimic natural thermal conditions. 


\section{APPLYING THE HEFLOW FRAMEWORK TO HYDROPOWER CONTEXTS}

The utility of frameworks used in conservation management is largely based on their broad applicability. Frameworks that provide a template for creating measurable objectives and operate across larger scales are needed. In addition, frameworks should provide the context for restoring aspects of river systems while considering current regulatory procedures. Stakeholders are applying increasing pressure on many hydropower dam owners to change plant operations to affect downstream river flows with the intention of providing better conditions for aquatic biological communities. Given that many tailwaters affected by hydropower operations provide acceptable (and in some cases exceptional) ecological services, there is a need for better understanding of the characteristics of flow variation that are amenable to healthy aquatic communities and those that may not be as conducive. These proposed changes should be assessed within a framework that provides balanced decision making for both hydropower and environmental stakeholders. Ensuring a truly sustainable outcome and the most optimal conditions for multiple stakeholders requires the establishment of a common framework that is utilized by all participants in the energy-water nexus.

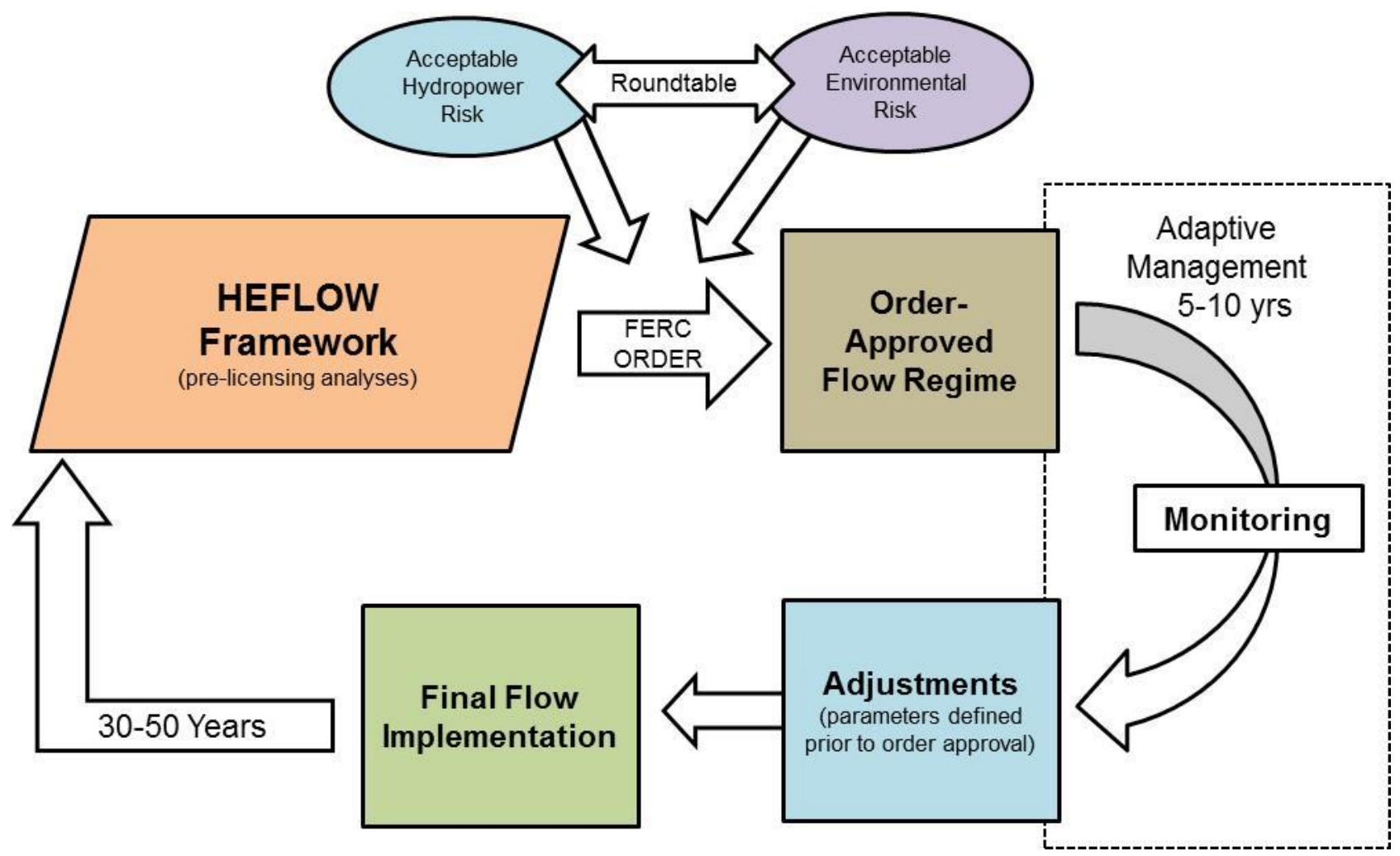

Figure 17. Implementation of flows following application of HEFLOW framework. Adaptive management should be used to monitor flows after implementation. However, for all parties to agree to adaptive management, hydropower and environmental stakeholders should both have some level of mutual perceived risk. Based on results of monitoring, collaborative decision making can be used to determine final flow regime for the length of the new license. 
The HEFLOW framework provides a template to organize tools, applications, and datasets useful in the process of identifying key hydrologic and ecologic indicators and identifying environmental needs based on ecological targets. The advantage of HEFLOW is that it expedites much of the information needs for the scoping element of the FERC process while efficiently organizing tools for the prescription and feasibility portions of the process. The actual implementation of new flow regimes follows the HEFLOW process (Figure 17). Although feasibility analyses provide some assessment of potential ecological benefit provided by alternative flow regimes, predictive analyses cannot and should not replace monitoring. Many times, population and ecosystem responses to flow regimes may take many years (sometimes decades) to come to full fruition; thus, monitoring becomes extremely important. Given the uncertainty of the ecological effectiveness of new flow regimes, we suggest an adaptive management strategy as follows: a 5-10 year 'grace period' of monitoring is conducted to evaluate ecological responses to the order-approve flow regime and that information be used within a collaborative process to adjust the final flow implementation (Figure 17). However, for the adaptive management design to be successful, both hydropower and environmental stakeholders must embrace some level of mutual perceived risk. For example, if monitoring suggests that the ecological benefits of the implemented flow regime are limited by water quality issues or by sustained peaking activity, then proposed modifications to the flow regime may include changes to the facility (e.g. $\mathrm{O}_{2}$ diffusers, intake structure) or reductions to peaking activities. Conversely, if monitoring suggests that the implemented flow regime results in no environmental improvement, then modifications may include reinstating aspects of the pre-licensing flow regime. For true adaptive management to work, participants must build a partnership based on trust, which requires both sides to accept risk.

\section{THE HEFLOW FRAMEWORK, MARKET ACCELERATION, AND ACCOMPLISHMENTS}

The HEFLOW framework addresses some of the needs of identifying environmental flow requirements in light of regulatory constraints, which other frameworks fail to address (see Section 2, page 8-9). However, as discussed in Section 2, the HEFLOW framework is not a complete paradigm shift. For example, HEFLOW uses a similar conceptual approach as ELOHA in that hydrologic classifications, hydrologic alterations, and flow-ecology relationships are developed. However, HEFLOW is different in the intent behind creating the structure, the elements that make up the framework, and how they are applied in implementing environmental flows. Specifically, HEFLOW differs from ELOHA in the following ways:

- HEFLOW addresses the importance of geomorphology and dam operation in providing context.

- Assessing the hydrologic and ecological condition within HEFLOW is meant to provide a relative comparison among projects and not suggest that return to pre-disturbance conditions is needed.

- Flow-ecology relationships are not univariate relationships. Rather, flow-ecology relationships within HEFLOW are developed within specific contexts using model building that addresses multiple factors (geomorphology, dam operations, habitat connectivity, etc).

- Flow-ecology relationships within HEFLOW include predicted ecological responses to flow improvements not just departures from pre-disturbance conditions. 
- Environmental flow recommendations are not solely dependent upon flow-ecology relationships. In contrast to ELOHA, environmental flow recommendations within HEFLOW are the result of prescription and feasibility analyses based on site-specific needs.

- The importance of water quality and reach geomorphology is explicitly addressed in feasibility assessments within HEFLOW. Streamflow should not be separated from river channel dynamics.

- HEFLOW is not meant to replace effective instream flow tools (e.g. IFIM). Rather, HEFLOW organizes how and when they should be applied.

A less obvious feature of HEFLOW is that it has the potential to expedite aspects of the FERC process, thereby creating efficiency and reducing costs for hydropower stakeholders. A large amount of time of the relicensing process is developing studies and analyses (i.e. scoping) that address information gaps. If poorly informed, expensive studies may be misguided and in turn, may result in environmental flows that are inadequate to improve ecological targets. HEFLOW expedites this process by providing a standardized approach to identifying the key hydrologic and ecological indicators of importance and isolating flow-ecology relationships that inform prescriptions and feasibility. It forces scoping and studies to be relevant and answer the most pressing questions. If the information and tool packages to implement HEFLOW are provided in central repositories and online interfaces, then these applications become the standardized means to mainstream relicensing and environmental impact associated with existing and new hydropower development. Another important facet of HEFLOW is that is establishes a comprehensive and coordinated research agenda to further the science of environmental flows.

Associated with HEFLOW are the production of large tabular and geospatial datasets that can inform and aid in coordinating existing and proposed research at DOE Laboratories.

Under the current scoped work by DOE, many accomplishments in research have been made that fill in various gaps associated with application steps of the HEFLOW framework (Figure 18). Most scoped elements have been researched (Figure 18). Some elements have been applied in case study settings (partial blue shading, Figure 18); however, wide-spread applicability requires building datasets for the entire U.S. to mainstream environmental flow determination. In other situations, research has been conducted at DOE-supported labs unrelated to IFP project, such as flow optimization, and can support the environmental flow determination process (full blue shading, Figure 18). In other situations, no research has been conducted for elements unrelated to the IFP project, such as building watershed geomorphic classifications, developing alternative flow scenarios for US hydropower facilities, and developing habitat fragmentation datasets, but technology exists to construct these resources. 


\begin{tabular}{l}
\hline Resource \\
\hline $\begin{array}{l}\text { Data } \\
\text { Hydrologic Classification }\end{array}$ Catershed Geomorphic Classification \\
Dam Operation Classification \\
Hydrologic Condition \\
Ecological Condition \\
Ecological Targets \\
Key Hydrologic/Ecological Indicators \\
Alternative Flow Scenarios \\
Habitat Connectivity \\
Reach Geomorphic Classes \\
Water Quality \\
Tools \\
Class Predictive Models \\
Eco-Class Linkage \\
Daily Statistics \\
Subdaily Statistics \\
Ecological Geospatial Datasets \\
Eco-Evidence Approaches \\
Flow-Ecology Relationships \\
Instream Flow Tools \\
Flow Optimization Toolbox
\end{tabular}

\begin{tabular}{|c|l|}
\hline \multicolumn{2}{|c|}{ Legend } \\
\hline DOE LAB & Researched during IFP \\
DOE LAB & Partially researched during IFP \\
DOE LAB & Partially researched during IFP; Full development unscoped \\
DOE LAB & $\begin{array}{l}\text { Researched by DOE LAB; unrelated to IFP } \\
\text { Researched by outside unrelated source } \\
\text { Not researched (Unscoped under current IFP) }\end{array}$ \\
\hline & $\begin{array}{l}\text { Not Applicable to Element } \\
* \text { IFP = Instream Flow Project (DOE-funded) }\end{array}$ \\
\hline
\end{tabular}

\begin{tabular}{l}
\hline Resources partially researched but full development unscoped \\
(partial blue shading) - refers to resources that have been built for \\
specific case studies to provide examples but not fully functional \\
for the entire US scale. \\
Resources researched by DOE LAB; unrelated to IFP (blue \\
shading) - refers to resources built under other DOE supported \\
work besides IFP. \\
Resources with very little research (partial red shading) - \\
Unscoped work that benefits from existing technology developed \\
through other DOE-support.
\end{tabular}

Figure 18. Accomplishments made by ORNL, PNNL, and ANL during the course of the Instream Flow Project (IFP) supported by DOE. Each cell represents a data set or tool that falls within a particular element/or application within the HEFLOW framework (see Figure 2 for reference). Accomplishments made related to- and unrelated to current DOE support are also provided. 
(THIS PAGE LEFT BLANK INTENTIONALLY) 


\section{REFERENCES}

Anderson, K.E., A.J. Paul, E. McCauley, L.J. Jackson, J.R. Post and R.M. Nisbet (2006) Instream flow needs in streams and rivers: the importance of understanding ecological dynamics. Frontiers in Ecology 4: $309-318$.

Annear, T., I. Chisholm, H. Beecher, A. Locke, et al. (2004) Instream flows for riverine resource stewardship, revised edition. Instream Flow Council, Cheyenne, WY.

Arthington A.H., S.E. Bunn, N.L. Poff, R.J. Naiman (2006) The challenge of providing environmental flow rules to sustain river systems. Ecological Applications 16: 1311-1318.

Arthington, A.H., J.L. Rall, M.J. Kennard and B.J. Pusey (2003) Environmental flow requirements of fish in the Lesotho Rivers using the DRIFT methodology. Rivers Research and Applications 19: 641-666.

Baker D.B., R.P. Richards, T.T. Loftus, and J.W. Krame (2004) A new flashiness index: characteristics and applications to Midwestern rivers and streams. Journal of the American Water Resources Association 40: 503-522.

Bevelhimer, M.S., V. Alavian, B. Miller, and G. Hauser (1997) Modeling thermal effects of operational and structural modifications at a hydropower facility on a premier trout stream in southwestern Montana. Waterpower: Proceedings of the International Conference on Hydropower 1997: 40-49.

Bevelhimer, M., R. A. McManamay, B. O’Connor (2013) Characterizing sub-daily flow regimes: implications of hydrologic resolution on ecohydrology studies. (in review - River Research and Applications).

Bovee, K. D., B. L. Lamb, J. M. Bartholow, C. B. Stalnaker, J. Taylor, and J. Henriksen (1998) Stream habitat analysis using the instream flow incremental methodology: U.S. Geological Survey Information and Technology Report 1998-0004. Reston, VA.

Brandt, S.A. (2000) Classification of geomorphological effects downstream of dams. Catena 40: 375-401.

Brown, C.A., A. Sparks, and G. Howard (2000) Palmiet River instream flow assessment: instream flow requirement for the riverine ecosystem. Proceedings of the IFR Workshop and Determination of Associated Dam Yields. Southern Waters Report No. G400-00-0499 to the South African Department of Water Affairs and Forestry: Pretoria, South Africa.

Bunn SE, and A.H. Arthington (2002) Basic principles and ecological consequences of altered flow regimes for aquatic biodiversity. Environmental Management 30: 492-507.

Bunte, K. (2004) State of the science review. Gravel migration and augmentation below hydroelectric dams: A geomorphic perspective. Report of Engineering Research Center, Colorado State University, Fort Collins, Co to Stream Systems Technology Center, USDA Forest Service, Fort Collins, Co.

Caissie, D. (2006) The thermal regime of rivers: a review. Freshwater Biology 51:1389- 1406.

Carlisle, D.M., D.M. Wollock, and M.R. Meador (2011) Alteration of streamflow magnitudes and potential ecological consequences: a multiregional assessment. Frontiers in Ecology and the Environment 9: 264-270.

Cushman, R.M. (1985) Review of ecological effects of rapidly varying flows downstream from hydroelectric facilities. North American Journal of Fisheries Management 5: 330-339. 
FERC (Federal Energy Regulatory Commission) (2013) Licensing processes. Available at:

http://www.ferc.gov/industries/hydropower/gen-info/licensing/licen-pro.asp. Accessed 18 April, 2013.

Filzmoser P., and M. Gschwandtner (2012) Package 'mvoutlier'. Multivariate outlier detection based on robust methods. Accessed September 11, 2012 at:

http://cran.r-project.org/web/packages/mvoutlier/mvoutlier.pdf.

Fitzhugh, T.W. and R.M. Vogel (2011) The impact of dams on flood flows in the United States. River

Research and Applications 27: 1192-1215.

Freeman, M. C., and P. A. Marcinek. 2006. Fish assemblage responses to water withdrawals and water supply reservoirs in piedmont streams. Environmental Management 38:435-450.

Frimpong, E.A. and P.L. Angermeier (2009) Fish Traits: A database of Ecological and Life-history traits of freshwater fishes of the United States. Fisheries 34: 487-495.

Frimpong, E.A., and P.L. Angermeier (2010b) Trait-based approaches in the analysis of stream fish communities. American Fisheries Society Symposium 73: 109-136.

Gordon E, and R.K. Meentemeyer (2006) Effects of dam operation and land use on stream channel morphology and riparian vegetation. Geomorphology 82: 412-429.

Gordon, N. D., T. A. McMahon, B. L. Finlayson, C. J. Gippel, and R. J. Nathan (2004) Stream hydrology. An introduction for ecologists, 2nd edition. John Wiley and Sons, West Sussex, England.

Grant, G. E., J. C. Schmidt, and S. L. Lewis (2003) A geological framework for interpreting downstream effects of dams on rivers. pp 209-225 In A Peculiar River, J.E. O‘Connor and G.E. Grant (eds.) American Geophysical Union, Water Science and Application 7.

Haas, N.A., B.L. O’Connor, J.W. Hayse, M.S. Bevelhimer, and T.A. Endreny (2013) Analysis of dailypeaking and run-of-river dam operations on flow variability metrics considering subdaily to seasonal time scales. (in review - Journal of the American Water Resources Association)

Hamblin, P.F., and S.O. McAdam (2003) Impoundment effects on the thermal regimes of Kootenay Lake, the Arrow Lakes Reservoir and Upper Columbia River. Hydrobiologia 504: 3-19, 2003.

Han, M., M. Fukushima, S. Kameyama, T. Fukushima, and B. Matsushita (2008) How do dams affect freshwater fish distributions in Japan? Statistical analysis of native and nonnative species with various life histories. Ecological Research 23:735-743.

Hendriksen J.A., J. Heasley, J.G. Kennen, S. Nieswand (2006) Users' manual for the hydroecological integrity assessment process software (including the New Jersey Assessment Tools). US Geological Survey Report 2006-1093.

Herbert, M. E., and F. P. Gelwick (2003) Spatial variation of headwater fish assemblages explained by hydrologic variability and upstream effects of impoundment. Copeia 2: 273-284.

Hoagstrom, C. W., J. E. Brooks, and S. R. Davenport (2008) Recent habitat association and the historical decline of Notropis simus pecosensis. River Research and Applications 24:789-803.

Jackson, D. A., P. R. Peres-Neto, and J. D. Olden (2001) What controls who is where in freshwater fish communities - the roles of biotic, abiotic and spatial factors. Canadian Journal of Fisheries and Aquatic Sciences 58: 157-170.

Kendy E., C. Apse, and K. Blann (2012) A practical guide to environmental flows for policy and planning with nine case studies in the United States. The Nature Conservancy. http://conserveonline.org/workspaces/eloha/documents/template-kyle. Accessed 18 July 
2012.

Kennard M.J., B.J. Pusey, J.D. Olden, S.J. Mackay, J.L. Stein, and N. Marsh (2010b) Classification of natural flow regimes in Australia to support environmental flow management. Freshwater Biology 55: 171-193.

King, J. and D. Louw (1998) Instream flow assessments for regulated rivers in South Africa using the Building Block Methodology. Aquatic Ecosystem Health and Management 1: 109-124.

Kondolf, G. M., J. C. Vick, and T. M. Ramirez (1996) Salmon spawning habitat rehabilitation on the Merced River, California: an evaluation of project planning and performance. Transactions of the American Fisheries Society 125: 899-912.

Krause, C. W., T. J. Newcomb, and D. J. Orth (2005) Thermal habitat assessment of alternative flow scenarios in a tailwater fishery. River Research and Applications 21:581-593.

Lessard, J. L., and D. B. Hayes (2003) Effects of elevated water temperature on fish and macroinvertebrate communities below small dams. River Research and Applications 19:721-732.

Liermann C.A.R., J.D. Olden, T.J. Beechie, M.J. Kennard, P.B. Skidmore, C.P. Konrad, and H. Imaki (2012) Hydrogeomorphic classification of Washington state rivers to support emerging environmental flow management strategies. River Research and Applications 28: 1340775.

Ligon, F. K., W. E. Dietrich, and W. J. Trush (1995) Downstream ecological effects of dams. BioScience 45:183-192.

Magilligan, F.J. and K.H. Nislow (2001) Long-term changes in regional hydrologic regime following impoundment in a humid-climate watershed. Journal of the American Water Resources Association 37: 1551-1569.

Magilligan F.J., and K.H. Nislow (2005) Changes in hydrologic regime by dams. Geomorphology 71: 6178.

Mathews, R., and B. D. Richter (2007) Application of the indicators of hydrologic alteration software in environmental flow setting. Journal of the American Water Resources Association 436: 1400-1413.

McCargo, J., and J. Peterson (2010) An evaluation of the influence of seasonal base flow and geomorphic stream characteristics on Coastal Plain stream fish assemblages. Transactions of the American Fisheries Society 139: 29-48.

McCartney, M. (2009) Living with dams: managing the environmental impacts. Water Policy 11:121139.

McManamay, R.A., M.S. Bevelhimer, E.A. Frimpong (2013a) US hydrologic classification applied to fish traits: a framework for developing flow-ecology hypotheses (in review - Ecohydrology).

McManamay, R.A., M.S. Bevelhimer, S-C. Kao (2013b) A new US hydrologic classification: a tool to stratify analyses in Ecohydrology (in review - Ecohydrology).

McManamay, R.A., D.J. Orth, C.A. Dolloff (2012) Revisiting the homogenization of dammed rivers in the southeastern US, Journal of Hydrology 424-425: 217-237.

McManamay, R. A., D. J. Orth, C. A. Dolloff, and M. A. Cantrell (2010) Gravel addition as a habitat restoration technique for tailwaters. North American Journal of Fisheries Management 30:1238-1257. 
McManamay, R.A., D.J. Orth, C.A. Dolloff, D.C. Mathews (2013c) Application of the ELOHA framework to regulated rivers in the Upper Tennessee River Basin: a case study. Environmental Management [online] DOI 10.1007/s00267-013-0055-3

McManamay, R.A., D.J. Orth, J. Kauffman, and M.M. Davis (2013d) A database and meta-analysis of ecological responses to stream flow in the South Atlantic region, Southeastern Naturalist 12 (5): 1-36. [online] http://www.eaglehill.us/SENAonline/sena-v12-mon5-2013.shtml

Meile T., J.L. Boillat, A. Schleiss (2011) Hydropeaking indicators for characterization of the UpperRhone River in Switzerland. Aquatic Sciences 73: 171-182.

Merz, J. E., and L. K. O. Chan (2005) Effects of gravel augmentation on macroinvertebrate assemblages in a regulated California river. River Research and Applications 21:61-74.

Merz, J. E., and J. D. Setka (2004) Evaluation of a spawning habitat enhancement site for Chinook salmon in a regulated California River. North American Journal of Fisheries Management 24:397-407.

Moir H.J., C.N. Gibbins, C. Soulsby, A.F. Youngson (2005) PHABSIM modelling of Atlantic salmon spawning habitat in an upland stream: testing the influence of habitat suitability indices on model output. River Research and Applications 21: 1021-1034.

NatureServe (2004), Downloadable animal datasets. NatureServe Central Databases. Available online at: www.natureserve.org/getData/dataSets/watershedHucs/index.jsp. Accessed 15, November 2011.

Nislow K.H., F.J. Magilligan, H. Fassnacht, D. Bechtel, and A. Ruesink (2002) Effects of dam impoundment on the flood regime of natural floodplain communities in the upper Connecticut River. Journal of the American Water Resources Association 38: 1533-1548.

Norris, R.H., J.A. Webb, S. J. Nichols, M.J. Stewardson, and E.T. Harrison (2012) Analyzing cause and effect in environmental assessments: using weighted evidence from the literature. Freshwater Science 31: 5-21.

Olden, J. D., and R. J. Naiman (2010) Incorporating thermal regimes into environmental flows assessments: modifying dam operations to restore freshwater ecosystem integrity. Freshwater Biology 55: 86-107.

Olden J.D., and N.L. Poff (2003) Redundancy and the choice of hydrologic indices for characterizing streamflow regimes. River Research and Applications 19: 101-121.

Poff N.L. (1996) A hydrogeography of unregulated streams in the United States and an examination of scale-dependence in some hydrological descriptors. Freshwater Biology 36: 71-91.

Poff, N. L., and J. D. Allan. (1995) Functional-organization of stream fish assemblages in relation to hydrological variability. Ecology 76: 606-627.

Poff N.L., and J.V. Ward. (1989) Implications of streamflow variability and predictability for lotic community structure - a regional-analysis of streamflow patterns. Canadian Journal of Fisheries and Aquatic Sciences 46: 1805-1818.

Poff N.L., and J.Z.H. Zimmerman (2010) Ecological responses to altered flow regimes: a literature review to inform the science and management of environmental flows. Freshwater Biology 55: 194-205.

Poff NL, J.D. Allan, M.B. Bain, J.R. Karr, K.L. Prestegaard, B.D. Richter, R.E. Sparks, J.C. Stromberg (1997) The natural flow regime: a paradigm for river conservation and restoration. BioScience 47: 769784. 
Poff N.L., J.D. Olden, D.M. Merritt, and D.M. Pepin (2007) Homogenization of regional river dynamics by dams and global biodiversity implications. Proceedings of the National Academy of Sciences of the United States of America 104: 5732-5737.

Poff, N. L., B. D. Richter, A. H. Arthington, S. E. Bunn, R. J. Naiman, E. Kendy, M. Acreman, C. Apse, B. P. Bledsoe, M. C. Freeman, J. Henriksen, R. B. Jacobson, J. G. Kennen, D. M. Merritt, J. H. O'Keeffe, J. D. Olden, K. Rogers, R. E. Tharme, and A. Warner. 2010. The ecological limits of hydrologic alteration (ELOHA): a new framework for developing regional environmental flow standards. Freshwater Biology 55:147-170.

Power M.E., A. Sun, G. Parker, W.E. Dietrich, and J.T. Wootton (1995) Hydraulic food-chain models. BioScience 45: 159-167.

Pozo, J., E. Orive, H. Fraile, and A. Basaguren (1997) Effects of the Cernadilla- Valparaiso reservoir system on the River Tera. Regulated Rivers-Research and Management 13: 57-73.

Price, R.E., and E. B. Meyer (1992) Water quality management for reservoirs and tailwaters: Operational and structural water quality techniques. Technical Report E-89-1. US Army Engineer Waterways Experimental Station, Vicksburg, MS.

Pringle C.M., M.C. Freeman, and B.J. Freeman (2000) Regional effects of hydrologic alterations on riverine macrobiota in the new world: tropical temperate comparisons. BioScience 50: 807-823.

Pyron, M., and T. E. Lauer (2004) Hydrological variation and fish assemblage structure in the middle Wabash River. Hydrobiologia 525: 203-213.

Pyron, M., and K. Neumann (2008) Hydrologic alterations in the Wabash River watershed, USA. River Research and Applications 24: 1175-1184.

Reid, S. M., N. E. Mandrak, L. M. Carl, and C. C. Wilson (2008) Influence of dams and habitat condition on the distribution of redhorse (Moxostoma) species in the Grand River watershed, Ontario. Environmental Biology of Fishes 81:111-125.

Richhter B.D., J.V. Baumgartner, J. Powell, D.P. Braun (1996) A method for assessing hydrologic alteration within ecosystems. Conservation Biology 10: 1163-1174.

Richter, B. D., J. V. Baumgartner, R. Wigington, D. P. Braun (1997) How much water does a river need? Freshwater Biology 37: 231-249.

Richter, B.D., M.M. Davis, C. Apse, and C. Konrad (2012) A presumptive standard for environmental flow protection. River Research and Applications 28: 1312-1321.

Richter, B.D., A.T. Warner, J.L. Meyer, and K. Lutz (2006) A collaborative and adaptive process for developing environmental flow recommendations. River Research and Applications 22: 297-318.

Roni, P., T. J. Beechie, R. E. Bilby, F. E. Leonetti, M. M. Pollock, and G. R. Pess (2002) A review of stream restoration techniques and a hierarchical strategy for prioritizing restoration in Pacific northwest watersheds. North American Journal of Fisheries Management 22:1-20.

Roni, P., K. Hanson, and T. Beechie (2008) Global review of the physical and biological effectiveness of stream habitat rehabilitation techniques. North American Journal of Fisheries Management 28:856-890. Rosgen D.L. (1994) A classification of natural rivers. Catena 22: 169-199. 
Roy, A.H., M.C. Freeman, B.J. Freeman, S.J. Wenger, W.E. Ensign, and J.L. Meyer (2005) Investigating hydrologic alteration as a mechanism of fish assemblage shifts in urbanizing streams. Journal of the North American Benthological Society 24: 656-678.

Sarriquet, P. E., P. Bordenave, and P. Marmonier (2007) Effects of bottom sediment restoration on interstitial habitat characteristics and benthic macroinvertebrate assemblages in a headwater stream. River Research and Applications 23: 815-828.

Sherman, B. (2000) Scoping Options for Mitigating Cold Water Discharges from Dams. CSIRO Land and Water, Canberra.

Snelder, T. H., F. Cattanẽo, A. M. Suren, B. J. F. Biggs (2004) Is the River Environment Classification an improved landscape-scale classification of rivers? Journal of North American Benthological Society 23: 580-598.

Sokal R.R. (1974) Classification - purposes, principles, progress, prospects. Science 185: 1115- 1123

Sowa S.P., G. Annis, M.E. Morey, D.D. Diamond (2007) A gap analysis and comprehensive conservation strategy for riverine ecosystems of Missouri. Ecological Monographs 77: 301-334.

Stalnaker, C., B.L. Lamb, J. Henriksen, K. Bovee, and J. Barthalow (1995) The instream flow incremental methodology: a primer for IFIM. National Biological Service Biological Report 29, Fort Collins, CO.

Tear, T.H., P. Kareiva, P.L. Angermeier, P. Comer, B. Czech, R. Kautz, L. Landon, D. Mehlman, K. Murphy, M. Ruckelshaus, J. M. Scott, and G. Wilhere. 2005. How much is enough? The recurrent problem of setting measurable objectives in conservation. BioScience 55: 835-849.

Tennant, D.L. (1976) Instream flow regimens for fish, wildlife, recreation and related environmental resources. Fisheries 1: 6-10.

Tharme R.E. (2003) A global perspective on environmental flow assessment: emerging trends in the development and application of environmental flow methodologies for rivers. River Research and Applications 19: 397-441.

Trush W.J., S.M. McBain and L.B. Leopold (2000) Attributes of an alluvial river and their relation to water policy and management. Proceedings of the National Academy of Sciences of the United States of America 97: 11858-11863.

Vaughn, C. C., and C. M. Taylor (1999) Impoundments and the decline of freshwater mussels: A case study of an extinction gradient. Conservation Biology 13: 912-920.

Vernon, C.R., E.V. Arntzen, M.C. Richmond, R.A. McManamay, T.P. Hanrahan, C.L. Rakowski (2013) GIS framework for large river classification to aid in the evaluation of flow-ecology relationships, PNNL-xxxx Report. Prepared for the U.S. Department of Energy under Contract DE-AC0576RL01830, February 2013.

Wehrly, K.E., M.J. Wiley, and P.W. Seelbach (2003) Classifying regional variation in thermal regime based on stream fish community patterns. Transactions of the American Fisheries Society 132: 18-38.

Winemiller K.O. (2005) Life history strategies, population regulation, and implications for fisheries management. Canadian Journal of Fisheries and Aquatic Sciences 62: 872-885.

Winemiller K.O., K.A. Rose (1992), Patterns of life-history diversification in North American fishes: implication for population regulation. Canadian Journal of Fisheries and Aquatic Sciences 49: 21962218 . 
WMI (Wildlife Management Institute) (2012) Northeast Regional Conservation Needs. Available at: http://rcngrants.org/. Accessed 15 April, 2010.

Wollock, D.M., T.C. Winter, G. McMahon (2004) Delineation and evaluation of hydrologic-landscape regions in the United States using geographic information system tools and multivariate statistical analyses. Environmental Management 34: 71-88.

Zimmerman, J.K.H., B.H. Letcher, K.H. Nislow, K.A. Lutz, and F.J. Magillan (2010) Determining the effects of dams on subdaily variation in river flows at a whole-basin scale. River Research and Applications 26: 1246-1260. 


\section{APPENDIX- ABSTRACTS OF DOE SUPPORTED INSTREAM FLOW PROJECT WORK}

$>$ Bevelhimer, M., R. A. McManamay, B. O'Connor (2013), Characterizing sub-daily flow regimes: implications of hydrologic resolution on ecohydrology studies, (in review - River Research and Applications).

Daas, N.A., B.L. O'Connor, J.W. Hayse, M.S. Bevelhimer, and T.A. Endreny (2013), Analysis of dailypeaking and run-of-river dam operations on flow variability metrics considering subdaily to seasonal time scales, (in review - Journal of the American Water Resources Association)

Environmental flows are an important consideration in licensing hydropower projects because operational flow releases can result in adverse conditions to downstream ecological communities. Flow variability assessments have typically focused on pre- and post-dam conditions using metrics based on dailyaveraged flow values. This study focused on examining flow variability metrics using subdaily flow data to assess environmental flow conditions resulting from changes in hydropower operations from dailypeaking to run-of-river. An analysis tool was developed to quantify subdaily to seasonal flow variability metrics and was applied to four hydropower projects that underwent operational changes based on regulatory requirements. Results indicate that the distribution of flows is significantly different between daily-peaking and run-of-river operations, that daily-peaking operations are flashier than run-of-river operations, and that these differences are seen using hourly-averaged flow datasets and are less pronounced or not noticeable using daily-averaged flow datasets. Of the flow variability components examined, the use of daily versus subdaily flow data impacted the analysis of rise and fall rates the most. This outcome has implications for the development of flow-ecology relationships quantify effects of rate of change on processes such as fish stranding and displacement, along with habitat stability. The quantification of flow variability statistics should be done using subdaily datasets and metrics as this accurately represents the nature of hydropower operations.

$>$ McManamay, R.A., M.S. Bevelhimer, E.A. Frimpong (2013), US hydrologic classification applied to fish traits: a framework for developing flow-ecology hypotheses (in review - Ecohydrology).

Classification systems are valuable to ecological management in that they organize information into consolidated units thereby providing efficient means to achieve conservation objectives. Of the many ways classifications benefit management, hypothesis generation has been discussed as the most important. However, in order to provide templates for developing and testing ecologically relevant hypotheses, classification systems created using environmental variables must be linked to ecological patterns. Herein, we develop associations between two recent US hydrologic classifications and fish traits in order to form a template for generating flow-ecology hypotheses and supporting environmental flow standard development. We observed tradeoffs in adaptive strategies for fish (reproductive and life history traits) across a spectrum of stable, perennial flow to unstable intermittent flow. In accordance with theory, periodic strategists were associated with stable, predictable flow whereas opportunistic strategists were more affiliated with intermittent, variable flows. Comparisons of the predictive capacity of hydrologic classifications with other frameworks suggested that spatially contiguous classifications with higher numbers of classes and in turn, higher regionality will tend to explain more information in ecological patterns. We developed linkages between the uniqueness of hydrologic character and ecological distinction among classes, which may translate into predictions between losses in hydrologic uniqueness and ecological community response. Ultimately, our results provide a template to develop and test flow- 
ecology hypotheses and support the presumption that environmental flow standards should be catered towards stream classes and ecological communities, therein.

McManamay, R.A., M.S. Bevelhimer, S-C. Kao (2013), A new US hydrologic classification: a tool to stratify analyses in Ecohydrology (in review - Ecohydrology).

Hydrologic classifications unveil the structure of relationships among groups of streams with differing stream flow and provide a foundation for drawing inferences about the principles that govern those relationships. Hydrologic classes provide a template to describe ecological patterns, generalize hydrologic responses to disturbance, and stratify research and management needs applicable to ecohydrology. We developed two updated hydrologic classifications for the continental US using two streamflow datasets of varying reference standards. Using only reference-quality gages, we classified 1715 stream gages into 12 classes across the US. By including more streamflow gages $(n=2618)$ in a separate classification, we increased the dimensionality (i.e. classes) and hydrologic distinctiveness within regions at the expense of decreasing the natural flow standards (i.e. reference quality). Greater numbers of classes and higher regional affiliation within our hydrologic classifications compared to that of the previous US hydrologic classification (Poff, 1996) suggested that the level of hydrologic variation and resolution was not completely represented in smaller sample sizes. Part of the utility of classification systems rests in their ability classify new objects and stratify analyses. We constructed separate random forests to predict hydrologic class membership based on hydrologic indices or landscape variables. In addition, we provide an approach to assessing potential outliers due to hydrologic alteration based on class assignment. Departures from class membership due to disturbance take into account multiple hydrologic indices simultaneously; thus, classes can be used to determine if disturbed streams are functioning within the realm of natural hydrology.

$>$ Vernon, C.R., E.V. Arntzen, M.C. Richmond, R.A. McManamay, T.P. Hanrahan, C.L. Rakowski (2013), GIS framework for large river classification to aid in the evaluation of flow-ecology relationships, PNNLxxxx Report. Prepared for the U.S. Department of Energy under Contract DE-AC05-76RL01830, February 2013.

Providing a means to quantitatively define flow-ecology relationships is integral in establishing flow regimes that are mutually beneficial to power production and ecological needs. This paper presents a geographic information system (GIS) framework for large river classification that is flexible, accurate, and easily integrated with Ecological Limits of Hydrologic Alteration (ELOHA) initiatives. A case study was conducted integrating the base geomorphic aspect of this framework with the Modular Aquatic Simulation System two-dimensional (MASS2) hydraulic model and field collected data to establish optimal juvenile salmonid rearing habitat under varying flow regimes throughout an impounded portion of the lower Snake River, USA. Defining regions of optimal juvenile salmonid habitat at varying flows was used to distinguish areas that have a high potential for the creation of additional shallow water habitat. Findings indicated that the potential to create additional shallow water habitat does exist for juvenile salmonid rearing regardless of the flow scenario (exceedence levels of 1, 25, 50, 75, and 99 percent) for the sample time frame (May - June 2011). The left-bank habitat of the lower Snake River was also found to be preferable for juvenile salmon rearing compared to right-bank habitat. The results from the case study suggest that the GIS framework is a capable tool when used to diagnose flow-ecology relationships. Additionally, an alternative hydrologic classification system is explored that couples well with the geographically independent nature of this GIS framework. Future applications of this framework are to utilize it in other large river systems throughout the contiguous United States. The framework also allows for the organization of large river data to be quickly accessed and used for multi-river comparison and analysis. The development of a backend database accompaniment within an interactive web platform would be highly beneficial to create a readily available and standardized mechanism to facilitate nationally spread classification efforts. 